J Dev Stud. 2018 ; 54(7): 1171-1195. doi:10.1080/00220388.2017.1380797.

\title{
Well Begun, But Aiming Higher: A Review of Vietnam's Education Trends in the Past 20 Years and Emerging Challenges
}

\author{
Hai-Anh H. Dang [economist with the Survey Unit] and \\ Development Data Group, World Bank and a non-resident senior research fellow with Center for \\ Analysis and Forecasting, Vietnam Academy of Social Sciences \\ Paul W. Glewwe [professor] \\ Department of Applied Economics, University of Minnesota
}

\begin{abstract}
Given its modest position as a lower-middle income country, Vietnam stands out from the rest of the world with its remarkable performance on standardized test scores, school enrollment, and completed years of schooling. We provide an overview of the factors behind this exemplary performance both from an institutional viewpoint and by analyzing several different data sources, some of which have rarely been used. Some of the highlights are universal primary school enrollment, higher girls' net enrollment rates, and the role of within-commune individual factors. We further discuss a host of challenges for the country-most of which have received insufficient attention to date.
\end{abstract}

\section{Keywords \\ education; assessment; enrollment; years of schooling; survey; census; Vietnam}

\section{Introduction}

Among developing countries, Vietnam has become known for its performance in education. Perhaps the most striking aspect of Vietnam's education is its students' performance on international assessments of mathematics and reading skills, relative to other countries at its level of income - or even with a much higher income. For example, in the 2015 PISA international assessment of skills of 15-year-old students in more than 70 countries and economies, Vietnam's scores were much higher than those of almost any developing country, and on par with those of several "developed" countries, including the U.S. and the U.K. This outstanding performance in math, reading, and science is shown in Figure 1, which plots countries mean test scores against their (log of) per capita GDP. Vietnam stands out from the overall trends and lies in the upper left corners of all the three graphs, suggesting that it is an outlier relative to all other countries that participated in the PISA. ${ }^{1}$

Correspondence to: Hai-Anh H. Dang.

1Vietnam's outstanding performance is not restricted to 2015 alone. Another graph using the PISA test score data in 2012 (Dang and Glewwe, 2017) provides qualitatively similar results. 
An education system may follow an elitist approach, which benefits just a select few rather than the general public (Bourguignon and Verdier, 2000; Grossman and Kim, 2003). If this held true for Vietnam, its performance seen above-while perhaps still being impressivewould be much less fascinating since it would be representative of a small, privileged part of the population. But remarkably, Vietnam's high-quality education performance is also accompanied by a higher-than-average quantity of school achievement. Compared to even a larger sample of other countries around the world, the mean years of schooling of Vietnam's adult population is higher than would be predicted by its per capita income (Figure 2). Furthermore, while data on secondary enrollment rates are not readily available for the country in a comparative setting (e.g., a cross-country database such as the World Bank's WDI database), its net primary school enrollment rate is also above the trend (Figure 3). As will be seen below, the country's enrollment rates are very close to 100 percent at both the primary and lower secondary levels, and its upper secondary net enrollment rate increased from 27 percent in the early 1990s to over 70 percent in recent years. This strong performance naturally raises the questions of what factors lie behind it, and whether this success can be replicated in other countries.

We aim in this paper to sketch an overview of these factors, both from an institutional viewpoint and using micro survey data. ${ }^{2}$ We do not attempt to provide an in-depth analysis of the causal relationships between these factors; rather we provide a broad-brushed picture of Vietnam's education system, describing basic trends that emerge over time. To flesh out these trends, we also supplement our overview by referring to more detailed studies where relevant.

In particular, we make three contributions to the literature. First, we sketch out the trends in Vietnam's performance in education over the last two decades. In contrast with most existing studies that either analyze shorter time periods, or rely on indicators calculated from second-hand sources, we offer direct estimates based on nationally representative household survey data spanning the period from 1992 to 2014. The high quality of the household survey data renders our estimates more reliable. Indeed, we are unware of any other study that has undertaken the long-run analysis of education trends for Vietnam provided in this paper. $^{3}$

Second, after establishing the trends in Vietnam's enrollment rates and student learning, we offer a basic, but intuitive, decomposition of their variation into variation at different levels, including student, commune, and province levels. We provide this analysis using both household survey data and national assessment data for students in grade 5. In the context of Vietnam, although the Ministry of Education and Training (MoET) is the government agency in charge of setting education policies for the country, it is each province's Department of Education and Training (DoET) that implements these policies, at times with varying levels of innovation. Thus by decomposing the variations of outcome variables into

\footnotetext{
${ }^{2}$ We focus in this paper on studying general education (from grade 1 to grade 12). For a recent collection of studies on higher education in Vietnam, see, for example, Tran et al. (2014).

${ }^{3}$ For example, a recent and comprehensive analysis of education trends over the past two centuries by Lee and Lee (2016) does not offer estimates for Vietnam.
} 
different components at the province, commune, and student levels, we can better understand their relative importance in children's educational accomplishments.

Finally, the insights gleaned from the analysis discussed above allow us to identify the challenges currently faced by Vietnam's education system, as well as set the stage for further research. We thus highlight some of the challenges and spell out promising areas of future research. Furthermore, we implement our analysis by pulling together various data sources that appear not to have been examined together before. Consequently, as a byproduct, we also provide in Appendix 1 a brief overview of the available data sources related to education that can be analyzed for further research. Notably, some of these data sets, such as the primary school census, appear to have been under-utilized, especially in combination with other data sets.

We find that Vietnam has significantly increased school enrollment at all school levels in the past 20 years, with virtually universal school enrollment at the primary level and almost universal enrollment at the lower secondary level. At the upper secondary level, the enrollment rate among school-age children remarkably almost tripled in the span of 14 years (from 1992-1993 to 2006), from only about one in four children to almost three out of four children. While girls' net enrollment rates were lower than those of boys by 10-15 percentage points in 1992-1993, from 2006 onwards the rates for girls have been above those for boys at both the lower and upper secondary levels. The primary net enrollment rate for ethnic minority groups has steadily caught up with that for that of ethnic majority groups, but enrollment gaps persist at the secondary level, especially at the upper secondary level.

The majority of the variation in school enrollment and completed years of schooling is due to variation at the individual level within communes; both variation in average rates across provinces and variation in average rates across communes within provinces play relatively minor roles. While school level factors appear to play a major role in determining students' test scores, this role seems to have diminished from 2001 to 2007. This was likely caused by a convergence in school quality within the country.

Nevertheless, despite Vietnam's impressive performance, we bring attention to several remaining challenges. These include limited school choice, low enrollment at the upper secondary level, and a strong need for strategic planning for systemic reforms.

The rest of this paper is organized as follows. We describe Vietnam's education system in the next section, before discussing the data and analytical framework in Section III. We analyze the trends and decomposition results for enrollment and learning achievement in Sections IV and V. Section VI examines current education policy issues and suggests future areas for research, and Section VII concludes.

\section{Overview of Vietnam's Education System}

This section provides an overview of Vietnam's education system, with a particular focus on some of its most salient features, including organization and finance, instruction time, and 
what we know from the existing studies on the returns to education. We pay particular attention to the evolution of the system over time.

\section{Organization and Finance ${ }^{4}$}

Starting around 1990, Vietnam entered a period of rapid growth, with annual GDP growth between 5 and 7 percent. During this period, Vietnam's government invested in education aggressively even as household payments continued to play a central role in education finance. By the late 1990s, enrollment rates in primary and secondary education had fully returned to the high levels attained in the mid-1980s, and since then Vietnam has seen continued gains in enrollment at all levels. This will be discussed in more detail below.

The finance and delivery of education in Vietnam occurs through a complex variety of modes, including both public and several varieties of private (referred to as "non-public" in Vietnam) education. Almost all primary schools and lower-secondary schools are entirely state-managed and are thus labeled "public." Yet at the upper-secondary levels there are both "public" and "non-public" schools, the latter of which account for 15 percent of all uppersecondary schools in the country (MoET, 2013). The number of "non-public" schools either "people-founded" (dân lập) schools, for which the state may provide land or subsidies, or self-sufficient private schools - is increasing, especially in urban areas.

The finance of public education rests on both government subsidies and other payment sources. Virtually all "public" primary and lower-secondary schools function on the basis of formal and informal payments. Despite central government norms, the manner in which primary education is financed varies across provinces and districts, and even within districts. These payments, which are made by parents, depend on the funding practices of provinceand district-level authorities and they also vary by schools. Indeed, variation in arrangements governing finance can sometimes be observed even across classes within the same school, even for classes at the same grade level.

In lower- and upper-secondary education, modes of education provision and finance are even more varied, and there has been particular movement toward diversification in uppersecondary education to expand the role of "non-public" schools. Again, however, the terms "public" and "non-public" must be treated with caution. Across all forms of secondary education, education payments comprise a mix of formal and (sometimes opaque) informal payments, and "extra study" (private tutoring) is pervasive (Dang, 2013). Generally, the size of payments increases with the level of education. A further layer of complexity is the diversity found across and within public schools with respect to curriculum, as is exemplified by the phenomenon of "high quality" alongside "normal" classrooms in the same public schools.

\section{Instruction Time}

In 2013, about 50 percent of primary schools were providing "full day" (6 hours) instruction; the other 50 percent received only "half day" ( 3.5 hours) instruction, with

\footnotetext{
${ }^{4}$ More detailed discussion of the country's education system and historical background is provided in London (2011), Hayden and Le (2013), and Dang and Glewwe (2017).
} 
schools usually operating two shifts. Extension of "full-day" schooling to poorer localities has proceeded slowly, which raises potentially major concerns for efforts at system-wide reforms; the reasons why it has not been fully implemented require further analysis and are beyond the scope of this paper.

That Vietnam has one of the shortest school days, and one of the shortest school years, in the world is somewhat misleading. In most areas - even rural areas - parents send their primary and secondary age children to varying amounts of "extra study" classes. ${ }^{5}$ As seen in Table 1.1 in Appendix 1, this phenomenon is not a new one; it dates back to at least the late 1990s, and possibly even earlier. It decreased in 2002 , but since then it has been increasing over time. Given the small share (and largely urban location) of the private education sector in Vietnam, private tutoring arguably represents households' best substitute for private education (Dang and Rogers, 2016), since households have been observed to be more willing to spend on education as their incomes rise (Glewwe and Patrinos, 1999). The time and resources devoted to this activity and the ways it is organized and/or regulated also vary across provinces. In addition to variation in the availablity of "full-day schooling," the high prevalence of extra study has raised equity concerns because poorer families may not be able to afford extra study classes (Dang, 2007, 2008). Even so, and despite its cost, extra study continues to be regarded as essential to success, perhaps partly owing to fear of discrimination and stigma from teachers or peers. However, the value of the material typically taught in "extra study" has recently been called into question (World Bank, 2014).

\section{Beneficial Impacts of Education}

Education has long been known to be indispensable for increasing individuals' human capital and wages. This is also generally true for the specific context of Vietnam, where returns to education appear to have increased after the Đổi Mối reforms (Liu, 2006; Oostendorp and Doan, 2013; Sakellariou and Fang, 2014). In particular, these returns have become higher for the poor over time, which indicates that policies to help the rural poor improve their education may help reduce the urban-rural divide in inequality (Nguyen et al., 2007; Le and Booth, 2014). More and higher-quality education also helps to narrow the gap in inequality between ethnic minority and ethnic majority groups (Dang, 2012; Nguyen et al., 2017). Higher education levels also result in larger wage premiums, especially for workers in state-owned firms (Imbert, 2013; Phan and Coxhead, 2013) or foreign firms (Fukase, 2014).

Furthermore, some indirect benefits of education are observed as well. For example, child labor can have negative and long-term effects on health outcomes (O'Donnell et al., 2005) and school attainment (Beegle, Dehejia, and Gatti, 2009); as such, keeping a child in school longer can have a positive effect on these outcomes. Education can also create room for personal emancipation and improves social equity for women (Muller, 2007). ${ }^{6}$

\footnotetext{
${ }_{5}^{5}$ See Dang and Rogers (2008) for an overview of the private tutoring phenomenon around the world.

${ }^{6}$ But there is also some evidence that there have been only modest increases in returns to years of education after the mid-2000s (Doan and Gibson, 2010).
} 


\section{Data and Analytical Framework}

Vietnam is fortunate in that there are many data sources that can be used to track its performance in education over the past 25 years and to investigate the possible causes of that performance. This section begins by briefly describing the data available for Vietnam from 1990 to 2014, and then presents a methodology for decomposing the variation in enrollment rates and test scores into province-level factors, community-level factors, and individuallevel factors.

\section{III.1. Data}

This paper analyzes three main sources of survey data, all of which are nationally representative surveys. The first source of data is the 1992-1993 and 1997-1998 Vietnam Living Standards Surveys (VLSS) and the 2002, 2004, 2006, 2008, 2010, 2012 and 2014 Vietnam Household Living Standards Surveys (VHLSS) (both surveys are referred to as VHLSS hereafter). The second source of data are reading and mathematics assessments of learning of Grade 5 students that were undertaken by Vietnam's Ministry of Education in 2001 and 2007, respectively. ${ }^{7}$ The third source of data are the 2012 and 2015 rounds of the Programme for International Student Assessment (PISA), which is conducted by the Organization for Economic Cooperation and Development (OECD). We offer more information on these and some other data in Appendix 1.

In addition to these main data sources, our analysis is also supplemented with data from several other sources, including the World Bank's World Development Indicators database (World Bank, 2017), UNESCO's WIDE database (UNESCO, 2017), and Vietnam's primary school census for the years between 2005 and 2011.

\section{III.2. Analytical Framework}

We decompose the variation in school enrollment and education achievement (including completed years of schooling and test scores) into variation at each of three levels province, commune (school), and child (or student) - as follows

$$
\tau_{y}^{2}=\tau_{p}^{2}+\tau_{s}^{2}+\tau_{i}^{2}
$$

We can then estimate the share of each level in the total variance as $\frac{\tau_{l}^{2}}{\tau_{y}^{2}}$, where $l=p$, $s$ or $i$. Knowing the relative contribution to the total variation in various education outcomes from each level can help provide useful policy advice. For example, if the school level explains a major share of the total variation, policies focusing on improving schools (rather than, say, policies that equalize conditions across provinces) would be likely to be more effective at raising educational outcomes. A useful feature of equation (1) is that it enables us to make comparisons across different datasets, as long as the education outcome variables and the

\footnotetext{
${ }^{7}$ Assessment data were also collected in 2011 and 2015, but given their potential problems of data quality, our discussion is limited to the data collected in 2001 and 2007.
} 
levels are similar for these datasets. This is especially relevant to our analysis of the VHLSS data and of the Grade 5 reading and mathematics assessments.

Equation (1) provides the unconditional decomposition of the variation in test scores into level-aggregated factors. We also examine the (more disaggregated) conditional correlations of education outcomes, using the following linear mixed model:

$$
Y_{i s p}=\alpha+\boldsymbol{\beta}^{\prime} \mathrm{Z}_{i s p}+\varepsilon_{i s p}
$$

where $Y_{i s p}$ is an education outcome such as school enrollment or test scores for individual $i$ in commune (or school) $s$ in province $p$. The vector of variables $\boldsymbol{Z}_{i s p}$ represents individual and household characteristics such as age, gender, ethnicity, household income, urban/rural residence, and the maximum education level achieved by the household head (that is, dummy variables indicating whether the head completed primary school, lower secondary school, upper secondary school, or college and/or above). In particular, $a+\beta Z_{\text {isp }}$ represents the fixed portion of the model that provides an overall regression line (or the population average conditional on the characteristics $\boldsymbol{Z}_{\text {isp }}$ ).

In a similar spirit to equation (1), the variance of the random effects portion of the model in equation (2) can be written out as follows

$$
\sigma_{i s p}^{2}=\sigma_{p}^{2}+\sigma_{s}^{2}+\sigma_{i}^{2}
$$

The three terms on the right-hand side of equation (3) represent the variances of the random effects at the province, commune, and child level, respectively, which are the sources of variation to the overall regression line that are contributed by unobserved factors at each of these levels. Alternatively, equation (3) can also be interpreted as the conditional version of equation (1), where after controlling for $\boldsymbol{Z}_{i j p}$ the remaining variation in test scores are decomposed into factors at the province, school, and student levels.

The linear mixed model presented in equation (2) offers several useful properties. First, its interpretation is straightforward since the associated relationship of the estimated coefficients on the fixed portion (i.e. the portion associated with the observable variables) can then be read off of the regression results just as with the standard OLS regression. Second, it is a generalized version of the commonly used random effects model in econometrics. ${ }^{8}$ Thus it is easy to generalize equation (2) to allow for contributions to education achievement from different levels of random effects, both conceptually and practically. In particular, the standard linear random effects model offers only two levels of random effects, but equation (2) offers three levels and can be readily extended to incorporate additional levels such as the regional level. In addition, it is also more

\footnotetext{
${ }^{8}$ If there are only two levels of unobserved factors in this model (for example, one at the individual level and the other at the commune level), equation (2) is equivalent to the standard (commune) random effects model commonly used in econometrics. See, for example, Skrondal and Rabe-Hesketh (2004) for a comprehensive treatment of hierarchical (multilevel) modelling.
} 
straightforward to decompose the variations in education achievement into different components due to the fixed portion or the random portion of the model.

\section{Trends and Patterns in Enrollment and Years of Completed Schooling since 1990}

\section{IV.1. Trends in School Enrollment}

Since the early 1990s, net enrollment rates have increased at both the primary and secondary levels and have reached 95 percent or more, as shown in Table 1. (All figures in this table were calculated using the VHLSS data sets). More specifically, the net primary enrollment rate in Vietnam increased from 85.6 percent in 1992-1993 to 93.7 percent in 1997-87, and then gradually increased to 98.0 percent by $2014 .{ }^{9}$ The lower secondary net enrollment rate also increased steadily over this time period, from 72.3 percent in 1992-1993, to 86.4 percent in 1997-1998, and then more gradually increasing to 94.8 percent in 2014.

Finally, the increase in enrollment at the upper secondary level since the early 1990s is nothing less than dramatic. In 1992-1993 the net enrollment rate was only 27.2 percent, but only five years later (1997-1998) it had virtually doubled to 53.2 percent. It reached 73.4 percent in 2006 and has stayed at about that level up until 2014. Thus in the span of 14 years (from 1992-1993 to 2006) the situation improved from only about one in four children of upper secondary school age (15-17 years old) enrolled in that level of schooling to almost three out of four children.

Given this increase in the "flow" of educated citizens, the "stock" of education for the adult population has also steadily increased. This is most dramatic for adults age 18-25, for whom the average years of schooling increased from 7.6 in 1992-1993 to 10.5 in 2014, a gain of about three years of schooling over a period of a little over 20 years. For adults between ages 26 and 65, the stock of education grew more slowly, from 6.5 years in 1992-1993 to 8.4 years in 2014, due to the fact that about half of the individuals in this age group in 19921993 were still in this age group in 2014, and so their stock of education did not change at all.

\section{IV.2. Variation in Enrollment Rates by Gender and Ethnicity}

The trends in enrollment rates discussed above are averages for the entire population; more can be learned by disaggregating by various socio-economic groups. To begin, Figure 4 shows trends over time disaggregated by gender. At the primary level, there are virtually no differences, given the high net enrollment rates that are now very close to 100 percent. Yet at the lower and upper secondary levels there is some variation. For both of these levels girls' net enrollment rates were lower than those of boys by 10-15 percentage points in 19921993, but about 10 years later, in 2004, the girls' rates had almost caught up to those of boys, and from 2006 onwards the rates for girls have been above those for boys at both the lower and upper secondary levels. This "reverse gender gap" is very small at the lower

\footnotetext{
${ }^{9}$ The net enrollment rate for any level of education is the number of children enrolled in that level of education who are in the age range associated with that level, divided by the number of all children in that age range. By definition this rate, expressed in percentage terms, cannot exceed $100 \%$.
} 
secondary level since the overall rate is getting very close to 100 percent $(95$ percent in 2014), but at the upper secondary level the gap is larger and seems to have increased in 2014 to 10 percentage points.

Another important issue in education in Vietnam is the gap between the ethnic majority groups Viet (Kinh) and Hoa (which respectively stand for ethnic Vietnamese and ethnic Chinese) ${ }^{10}$ and (disadvantaged) ethnic minority groups. The changes in this gap over time are shown in Figure 5. At the primary level this gap has decreased dramatically since the early 1990s. In particular, in 1992-1993 the primary net enrollment rate for ethnic Vietnamese was about 30 percentage points higher than those of ethnic minorities (90 percent versus 60 percent), but this gap decreases in almost every subsequent year for which household survey data are available, so that by 2014 the gap is only 2 percentage points as the net primary enrollment rate is very close to 100 percent.

Yet at the secondary level the gaps persist. For lower secondary school the gap was about 14 percentage points in 1992-1993 (60 percent versus about 74 percent). This gap was reduced to a little under 10 percentage points by 1997-1998 but since then this gap has persisted even as the overall rate gradually has steadily increased since the turn of the century.

At the upper secondary level the gap gradually closed from the early 1990s to 2004, but starting in 2006 the gap markedly increased until about 2010, after which the large gap of about 30 percentage points has held steady. Particularly worrisome is that the increase in the gap since 2004 is almost completely due to decreasing upper secondary enrollment rates among ethnic minorities, as opposed to being due to increased enrollment of the ethnic majority. The large increase in this gap in recent years is an important question for future research.

\section{IV.3. Sources of Variation in Student Enrollment and Years of Schooling}

The decomposition described in equation (1) of Section III can be used to understand further the nature of variation in student enrollment and years of schooling.

To begin, Panel A in Figure 6 shows, for each year from 1992 to 2014, the decomposition of variation in net primary school enrollment into three components: variation in the mean net enrollment rates across provinces (the blue bars, which are at the bottom of the diagram); within-province variation in the mean enrollment rates at the community level (the maroon bars just above the blue bars); and within-commune variation in the enrollment status of individual children of primary school age (the green bars at the top of the figure). The striking finding, which holds for all years, is that 80-90 percent of the variation is within communes (at the child level), and there is very little difference in average enrollment rates across provinces or even across communes within provinces. Moreover, what little variation there is at the province and commune level seems to decrease over time. This is not particularly surprising as the overall net enrollment rate gets closer to 100 percent; the few children who are still not enrolled are spread relatively evenly across provinces and communes within provinces.

\footnotetext{
${ }^{10}$ The Hoa ethnic group is usually considered part of the major Viet ethnic group because of their high degree of assimiliation.
} 
A similar finding holds for the secondary enrollment rate, for which the decomposition results are shown in Panel B of Figure 6. (Note that these results combine lower and upper secondary school.) Again, about 80 percent of more of the variation in (net) secondary school enrollment is due to variation at the individual level within communes; variation in average rates across provinces, or in average rates across communes within provinces, plays a relatively minor role. The one difference, relative to the findings for primary schools, is that there is no obvious change over time in the patterns found in this decomposition.

Ultimately, years of schooling of adults may be of more importance than enrollment rates of school-age children, so Panel A of Figure 7 examines the variance decomposition of years of schooling of adults age 15 to 25 . While it is still the case that more than half of the variation occurs at the individual level, variation across communes within provinces plays a sizeable role, accounting for roughly 25 percent of the variation. Variation in mean years of schooling across provinces, on the other hand, contributes only about 10 percent of the total variation and that contribution is slowly decreasing over time. ${ }^{11}$

\section{IV.4. Decomposition into Household and Community Characteristics}

This subsection presents estimates of $\beta$ in equation (2), or the estimated coefficients on the observed factors associated with primary and secondary school enrollment, and years of schooling attained for individuals age 15-25, using nine household surveys that cover the time period from 1992-1993 to 2014. As earlier discussed, a major share of the variation in education outcomes is explained at the individual (or household) level. Thus we will probe more deeply into some of the key individual-level variables, with particular focus on how the relationship between these variables and enrollment or years of schooling attained has changed over time.

Table 2 presents estimates of the linear mixed models of enrollment for children of primary school age, that is children age 6-10 years old. In 1992-1993, the following variables had strong predictive power: age (and its square), ethnic minority status, household per capita expenditures (which can be interpreted as an income or wealth effect), and the level of education of the head of household (the omitted category being not completing primary education). The overall trend in Table 2 is that these variables have less predictive power over time, and some lose statistical significance. For example, the coefficients on age and its square in 2014 are only about one fourth or one fifth of their sizes in 1992-1993. Also, ethnic minority status becomes statistically insignificant, and the point estimate switches from negative to slightly (and insignificantly) positive. The impact of per capita expenditures also decreases to about one third of its size in the 1992-1993 survey, although it increases somewhat from 2012 to 2014. Finally, in 2014 only one of the four education level variables retains statistical significance, and the coefficient on that variable (for lower secondary education), is only a little more than one tenth of what it was in 1992-1993.

The process underlying the reduction in the explanatory power of the variables in Table 2 is that the primary net enrollment rate is approaching 100 percent, as seen in Table 1, so there is less and less variation over time for these variables to explain. Figure 5 showed how the

\footnotetext{
${ }^{11}$ Estimation results for the conditional variance (using equation (3)) are qualitatively similar (Dang and Glewwe, 2017).
} 
rates for ethnic minority and non-minority students are becoming more equal over time, which explains the reduction in the size of the associated coefficient over time in Table 2 and its loss of statistical significance.

A similar pattern is seen for some, but not all, variables in the estimates shown in Table 3 of the factors associated with enrollment in secondary school for children age 11-17, the age range corresponding to that level of education. ${ }^{12}$ For example, the estimated coefficient for households' per capita expenditures falls from about 15.8 in 1992-1993 to 9.9 in 2014, a decline of almost 40 percent. Similarly, the influence of parental education declines, but still retains statistical significance; for example the coefficient on completing upper secondary school declines from 27.1 to 17.4 .

Perhaps the most interesting change over time in the factors associated with secondary education is that, controlling for other factors, the situation has changed from one where boys were more likely to be enrolled than girls (from 1992-1993 to 2004) to one where girls are more likely to be enrolled than boys (starting in 2006). This is not surprising given the patterns seen in Figure 4. Overall, lower secondary enrollment rates are getting closer to 100 percent and so many explanatory variables have a diminished effect, although none loses statistical significance since there is still a large amount of variation to explain.

Finally, Table 4 examines the factors associated with years of schooling, and how they have changed over time, for individuals age 15-25 years old (most of whom had already finished their schooling). Except for a temporary reversal in sign in 1998, the influence of age does not show any particular change over time. In contrast, the reversal from favoring boys and men to favoring girls and women is found, just as in Table 3 (although there is a lag since years of schooling is a "stock" variable, not a "flow" variable and thus it take longer to change over time). Differences by ethnic minority status fluctuate over time with no longterm trend, although there was a temporary drop in predictive power in 2004 and 2006.

From the point of view of equity, the changes over time in the associations of household per capita expenditures and the education level of the head of the household seem to move in opposite directions. In particular, the impact of (the log of) per capita expenditures increases rather dramatically from 1992-1993 to 2004, increasing from 1.01 to 1.95 , but since that time it has decreased somewhat to 1.42 in 2014 . This is somewhat disappointing in terms of reducing inequalities in educational outcomes, since the impacts of household per capita expenditures is around 40 percent higher in 2014 than in 1992-1993. On a more positive note, the influence of parental education has dropped dramatically over time, especially from 1992-1993 to 2002, so that its influence since about 2002 is less than half of what it was in 1992-1993.

${ }^{12}$ Dang and Glewwe (2017) offer detailed estimation results and more discussion for the lower secondary level and the upper secondary level. 


\section{Trends and Patterns in Learning/Achievement since $\mathbf{2 0 0 0}$}

\section{V.1. Trends in Learning/Achievement}

While Vietnam's performance in attaining high levels of school enrollment and high completed years of schooling have attracted considerable attention, even more attention has been given to its performance in terms of student learning as measured by test scores, especially on the 2012 and 2015 PISA assessments. There is relatively little information available on trends in student learning over time; the main source of information on students' academic skills over time in Vietnam is that country's assessments of Vietnamese language and math skills of grade 5 students in 2001 and 2007.

We briefly discuss the results from the Grade 5 assessment data, where the test scores have been normalized so that the mean is approximately zero and the standard deviation is approximately one for the 2001 test scores, and the 2007 test scores are standardized by the distribution of 2001 test scores. For Vietnamese language skills, the test scores of grade 5 students increased by 0.22 standard deviations of the distribution of test scores in 2001 in the six years between 2001 and 2007. For mathematics, the increases were almost twice as high, an increase of 0.40 standard deviations. These are very large increases over only six years. Note that the data from Table 1 show that the primary school enrollment rate increased slightly, from about 93 percent in 2002 to about 96 percent 2006 and 2008, over the time period covered by these two Grade 5 assessments. Presumably the additional students who were enrolled in 2007 were relatively weak students, whose enrollment would lower test scores, not raise them. So this increase in learning may be slightly underestimated.

\section{V.2. Decomposition into Household, School and Community Characteristics}

To understand the variation in the Grade 5 assessment test scores, Panels B and C of Figure 7 decompose the overall variation in those scores into variation across provinces (dark blue bar), variation across schools within provinces (maroon bar), and variation across students within schools, separately by year and by test (math or Vietnamese). As with years of schooling and enrollment rates, variation in mean test scores across provinces plays little role, about 10-15 percent. However, variation across schools within provinces is quite large in 2001 for both tests, accounting for about 40-50 percent of the overall variation. Finally, variation across students within schools is well below 50 percent of total variation in 2001, but by 2007 this had increased to almost 60 percent. Thus school level factors appear to play a major role in determining students' test scores, but this role seems to be diminishing over time, at least from 2001 to 2007.

One possible explanation for this decreased role of schools is that there may be a convergence in school quality within the country. Indeed, the school census data that were collected from 2005 to 2011 provide some supportive evidence for this hypothesis. Figure 8 shows that the percentage of schools that meet national standards of quality has steadily increased over this time period, from about 13 percent in 2005 to almost 25 percent in $2011 .^{13}$

\footnotetext{
${ }^{13}$ This result also concurs with a recent study that examined the Young Lives data (Rolleston and Krutikova, 2014), which finds that disadvantaged students receive relatively equitable access to school quality.
} 
Finally, Table 5 examines the explanatory power of some variables for test scores in the Grade 5 assessment data. There are some changes over time in the explanatory power of variables that are similar to the changes seen in enrollment rates in Tables 2 and 3. In particular, girls performed less well than boys on the mathematics test in 2001, but by 2007 they outperformed boys. For the reading test girls outperform boys in both years. However, in contrast to Tables 2 and 3, the role played by parental education seems to have increased over time, which could reduce equity in students' education outcomes. Finally, two additional worrisome trends that stand in contrast to the findings in Tables 2 and 3 are the increased gap between ethnic majority and ethnic minority students over time, and the stronger explanatory power of wealth over time.

\section{Further Reflections on Current Education Policy Issues in Vietnam}

This section provides some further reflections on several current issues concerning the Vietnamese education system, particularly in comparison with other countries.

\section{Classroom Hours and Private-Public Partnerships in Education}

As impressive as Vietnam's education performance has been, there are areas in which its education system is deemed to be underperforming. One key area is that, in many primary schools, the school day is very short. Our calculation using the Primary School Census database suggests that more than half of all primary students in Vietnam attended classes with 5 half-day sessions per week in the school year 2011-12. Extension of "full-day" schooling to poorer localities has proceeded slowly, which raises potentially major equity concerns. This shortage of instruction time could result in increased household investment in private tutoring classes for their children, as discussed earlier. Figure 9 provides further comparative evidence by plotting the number of average tutoring hours against the number of average classroom hours, both per week, for all countries that participate in the 2012 PISA. ${ }^{14}$ Two observations based on this figure are of particular importance. First, more classroom hours are generally associated with fewer tutoring hours. This global trend is also supported by recent evidence from urban China that increased public spending on basic education is associated with significant reductions in household spending on private tutoring (Yuan and Zhang, 2015). Second, Vietnam ranks around the middle of the PISA sample for the number of classroom hours in language, math, and science (that is, 10 hours), but it is an extreme outlier in terms of tutoring hours; its six hours of tutoring per week is three times higher than the expected number of tutoring hours on the trend line.

These disparities between "full-day" and "half-day" in access to (high-quality) education could well be responsible for the learning gaps across different socioeconomic groups (World Bank, 2012a), some of which appear to be increasing over time (e.g. the gap between ethnic minority and ethnic majority students in learning, as measured by test scores). Clearly, one solution to this issue is to continue the drive to extend school hours, or the number of schools that offer full-day schooling. This appears to be the long-term and most desirable solution.

\footnotetext{
${ }^{14}$ We show data from the 2012 PISA since there are no data on classroom hours for Vietnam in the 2015 PISA.
} 
However, given the typical rigid public education system (at least in the short-run), another solution is to better mobilize resources from the private sector to develop private-public partnerships in education. There are multiple advantages of this approach, including more competition in the education market, flexible arrangements, and more options for the government to improve education quality (Patrinos, Barreira-Osorio, and Guaqueta, 2009). Indeed, as discussed earlier, private education is a small component of the education system in Vietnam, especially in rural areas, and private tutoring is the only-albeit second-bestalternative available to the majority of Vietnamese households. In fact, Dang and Rogers (2016) argue that it is the only choice variable for maximizing a rural household's utility function regarding their children's education.

Thus expanding education choices (e.g., through more incentives to nurture the growth of the private sector in education) can help better satisfy household demand for education, which is revealed by the frequent use of private tutoring. This in turn can lead to more efficient allocation and development of human resources, which was observed to have occurred in other developing countries such as Colombia (Angrist et al., 2006) and India (Muralidharan and Sundararaman, 2015). (But also note that a recent review by Urquiola (2016) finds mixed effects of private schools in other contexts, which suggests that these effects may be context-specific and no conclusive findings have been reached yet on the impacts of private school versus public school in general).

\section{Quantity versus Quality of Education}

Given its income level, Vietnam has achieved better-than-average net primary school enrollment (Figure 2) as well as years of schooling (Figure 3) compared to other countries. Its net secondary school enrollment rates are also strong and are more than 90 percent and 70 percent, respectively, at the lower secondary level and upper secondary level (Table 1). These compare favorably with an average net secondary enrollment rate of 70 percent for 142 countries at different income levels in the WDI database for the period 2010-2015 (our calculations).

Nevertheless, when we plot test scores against the enrollment rate for the 15-year-old population for the PISA data (Figure 10), Vietnam is also an outlier for enrollment for the sample of 72 countries and economies in the PISA. ${ }^{15}$ In fact, Vietnam has the lowest enrollment ("coverage") rate in the PISA sample, which clearly stands out from the global trend of improving both the quantity and quality of education (that is, the fitted line slopes upward suggesting a positive relationship between enrollment and test scores). ${ }^{16}$

A question then naturally arises. Moving forward, given its resource constraints (as a country with a relatively low level of GDP per capita) should Vietnam focus more on improving its quantity of education (e.g., increased enrollment) or its quality of education (e.g., better test scores)? While there may be concerns about a tradeoff between the quantity

\footnotetext{
${ }^{15}$ Enrollment rate is defined as the coverage rate of the PISA sample out of the 15-year-old population in each country (OECD, 2016). Further discussion of the difference between the PISA enrollment rate and those in Table 1 is beyond the scope of this paper, and we provide a more detailed investigation in a separate paper (Dang, Glewwe, Lee, and Vu, 2017).

${ }^{16}$ Everything else equal, countries' incomes are usually positively correlated with test scores and enrollment/coverage rates, which can result in this positive correlation.
} 
of education and the quality of education, there are instances where no such tradeoff has been found in developing and developed countries alike. For example, Duflo (2001) finds that a large-scale school construction program in Indonesia helped increase both enrollment rates and wages. An expansion of the independent-school sector from a strong monopoly of public schools was also found to improve average performance at the end of compulsory school, as well as long-run educational outcomes, in Sweden (Böhlmark and Lindahl, 2015).

\section{Systemic versus Piecemeal Reforms}

A recent approach to education reform proposes that the system as a whole be made coherent for optimal operation, rather than have piecemeal changes be implemented that may not fit into the overall functioning of the system (Pritchett, 2015; Andrews, Pritchett, and Woolcock, 2017). Seen in this light, the country's education system has much room for improvement. In particular, since Vietnam's GDP in 2010 was comparable to that of South Korea, and less than half of Singapore, in 1970-also top performing countries in the PISA - these countries can perhaps provide valuable lessons for Vietnam. Compared to the systems of South Korea and Singapore, Vietnam's education system scores well in terms of service delivery, but it lags behind in strategic planning and system oversight (World Bank, 2012b), which respectively call for better coordination among the key stakeholders in the education system (e.g., schools, parents, employers) and efficiency and equity in funding allocation. ${ }^{17}$

The latter issue is highlighted by the complex system of education finance, under which the cost of schooling may be a hardship for lower income families. Our estimation results show that, while there is evidence for a steadily weaker household income (wealth) impact on for primary and secondary school enrollment (Tables 2 and 3), there is, in fact, a stronger household income impact over time on mean years of schooling and Grade 5 test scores (Tables 4 and 5). This worrisome trend suggests a widening gap for the latter educational outcomes between poor and better off households.

Furthermore, virtually all "public" primary and lower-secondary schools in Vietnam function on the basis of both formal and informal payments. Despite central government norms, the manner in which primary education is financed varies across provinces and districts, and even within districts. These payments, which are made by parents, depend on the funding practices of province- and district-level authorities and they also vary by schools. Indeed, variation in arrangements governing finance can sometimes be observed even across grades within the same school, or even for classes at the same grade level. At the same time, commune-level and province-level factors account for an increasing share of the total variation in the education outcomes, from less than 20 percent for enrollment (Figure 6) to around 40 percent for mean years of schooling and Grade 5 test scores (Figure 7). These figures can be potentially reduced with the appropriate public policy interventions, and more efficient and equitable resource allocation would improve the functioning of the whole system. ${ }^{18}$

\footnotetext{
${ }^{17}$ Strategic planning also includes articulating a strategic direction and prioritizing a demand-led approach for development of the workforce, and system oversight includes diversifying pathways for skills acquisition and ensuring relevant and reliable standards (World Bank, 2012b).
} 


\section{Conclusion}

Vietnam's high performance in education demonstrates that low and middle income countries are not necessarily condemned to a "low-level equilibrium" with high enrollment but low student learning. The question is whether its success can be explained, and more importantly whether it can be replicated in other developing countries. In particular, the fact that Vietnam has one of the lowest enrollment rates in the PISA sample does not detract from its outstanding performance, but rather can contribute to the ongoing policy dialogue for the country's future trajectories.

This paper did not attempt to explain Vietnam's successful performance in education, but it does provide a launching point for future research to do just that by describing Vietnam's education system, using existing data to show trends in Vietnam's performance in the last 25 years, and by providing some initial analysis to understand the sources of variation in Vietnam's enrollment rates and student learning. The paper has also pointed out some challenges faced by Vietnam's education system that are also worthy of future research. Both types of research will be of interest to anyone interested in education in developing countries.

\section{Acknowledgments}

We would like to thank the editor Richard Palmer-Jones, two anonymous referees, Mai Thi Hong Bo, Francois Bourguignon, Michael Crawford, Joan DeJaeghere, Harry Patrinos, Lant Pritchett, Michel Welmond, Michael Woolcock, Wei Aun Yap, and participants at the conference "Enhancing the Quality of Service Delivery" organized at the World Bank Global Knowledge and Research Hub in Kuala Lumpur, Malaysia for useful comments on previous versions. We would also like to thank Huong Dang for capable research assistance, and the RISE Research Programme for its support. Some sample data sets and the do file that provides all the analysis in this paper can be downloaded from the website https://sites.google.com/site/haianhhdang/.

\section{References}

Andrews, M., Pritchett, L., Woolcock, M. Building State Capability: Evidence, Analysis, Action. New York, NY: Oxford University Press; 2017.

Angrist J, Bettinger E, Kremer M. Long-term educational consequences of secondary school vouchers: Evidence from administrative records in Colombia. American Economic Review. 2006; 96(3):84762.

Attfield I, Vu BT. A rising tide of primary school standards-The role of data systems in improving equitable access for all to quality education in Vietnam. International Journal of Education Development. 2013; 33:74-87.

Beegle K, Dehejia R, Gatti R. Why should we care about child labor? The education, labor market, and health consequences of child labor. Journal of Human Resources. 2009; 44(4):871-889.

Böhlmark A, Lindahl M. Independent schools and long-run educational outcomes: Evidence from Sweden's large-scale voucher reform. Economica. 2015; 82:508-551.

Bourguignon F, Verdier T. Oligarchy, democracy, inequality and growth. Journal of Development Economics. 2000; 62(2):285-313.

Dang H-A. The determinants and impact of private tutoring classes in Vietnam. Economics of Education Review. 2007; 26(6):684-699.

Dang, H-A. Private Tutoring in Vietnam: An Investigation of its Causes and Impacts with Policy Implications. Saarbrucken, Germany: VDM Verlag Dr. Mueller Publishing House; 2008.

${ }^{18}$ See also World Bank and MPI (2016) and Dang and Glewwe (2017) for discussion on related issues with education and skills for the labor market. 
Dang, H-A. Vietnam: A widening poverty gap for ethnic minorities. In: Hall, G., Patrinos, H., editors. Indigenous Peoples, Poverty and Development. New York: Cambridge University Press; 2012. p. 304-343.

Dang, H-A. Private tutoring in Vietnam: A review of current issues and its major correlates. In: Aurini, J.Dierkes, J., Davis, S., editors. Out of the Shadows: The Global Intensification of Supplementary Education. United Kingdom: Emerald Press; 2013. p. 95-127.

Dang, H-A., Glewwe, P. World Bank Policy Research Paper \# 8112. Washington, DC: The World Bank; 2017. Well begun, but aiming higher: a review of Vietnam's education trends in the past 20 years and emerging challenges.

Dang H-A, Rogers H. The growing phenomenon of private tutoring: Does it deepen human capital, widen inequalities, or waste resources? World Bank Research Observer. 2008; 23(2):161-200.

Dang H-A, Rogers H. The decision to invest in child quality over quantity: Household size and household investment in education in Vietnam. World Bank Economic Review. 2016; 30(1):104142.

Dang H-A, Glewwe P, Lee J, Vu K. What explains Vietnam's exceptional performance in education relative to other countries? Analysis of the PISA data. 2017 Unpublished manuscript.

Doan T, Gibson J. Return to education in Vietnam during the recent transformation. International Journal of Education Economics and Development. 2012; 3(4):314-329.

Duflo E. Schooling and labor market consequences of school construction in Indonesia: Evidence from an unusual policy experiment. American Economic Review. 2001; 91:795-813.

Fukase E. Foreign wage premium, gender and education: Insights from Vietnam household surveys. World Economy. 2014; 37:834-855.

General Statistical Office (GSO). Niên Giám Thống Kê 2015. Hanoi: Statistical Publishing House; 2016. (Statistical Yearbook of Vietnam 2015)

Glewwe P, Patrinos HA. The role of the private sector in education in Vietnam: Evidence from the Vietnam Living Standards Survey. World Development. 1999; 27(5):887-902.

Grossman HI, Kim M. Educational policy: Egalitarian or elitist? Economics \& Politics. 2003; 15:225246.

Hayden, M., Le, TNL. The education system in Vietnam: A need to improve quality. In: Brock, C., Symaco, L., editors. Education in South-east Asia. London: Bloomsbury Academic; 2013. p. 323-344.

Imbert C. Decomposing the labor market earnings inequality: The public and private sectors in Vietnam, 1993-2006. World Bank Economic Review. 2013; 27(1):55-79.

Le TH, Booth AL. Inequality in Vietnamese urban-rural living standards, 1993-2006. Review of Income and Wealth. 2014; 60:862-886.

Lee J-W, Lee H. Human capital in the long run. Journal of Development Economics. 2016; 122:147169.

Liu AYC. Changing wage structure and education in Vietnam, 1992-98. Economics of Transition. 2006; 14:681-706.

London, JD., editor. Education in Vietnam. Singapore: Institute of Southeast Asian Studies; 2011.

Ministry of Education \& Training. (MoET). Thống Kê Giáo Dục 2013. 2013. (Educational Statistics 2013). Retrieved from http://pbc.moet.gov.vn/?page $=11.11 \&$ view $=5251$

Müller TR. Education and gender in revolutionary societies: Insights from Vietnam, Nicaragua, and Eritrea. Compare: A Journal of Comparative and International Education. 2007; 37(5):635-650.

Muralidharan K, Sundararaman V. The aggregate effect of school choice: Evidence from a two-stage experiment in India. Quarterly Journal of Economics. 2015; 130(3):1011-1066.

Nguyen C, Griffin P. Factors influencing student achievement in Vietnam. Procedia Social and Behavioral Sciences. 2010; 2:1871-1877.

Nguyen BT, Albrecht JW, Vroman SB, Westbrook MD. A quantile regression decomposition of urbanrural inequality in Vietnam. Journal of Development Economics. 2007; 83(2):466-490.

Nguyen H-T-M, Kompas T, Breusch T, Ward MB. Language, Mixed Communes, and Infrastructure: Sources of Inequality and Ethnic Minorities in Vietnam. World Development. 2017; 96:145-162. 
O'Donnell O, Rosati FC, van Doorslaer E. Health effects of child work: Evidence from rural Vietnam. Journal of Population Economics. 2005; 18:437-467.

OECD. PISA 2015 Results (Volume I): Excellence and Equity in Education. Paris: Organization of Economic Cooperation and Development; 2016.

Oostendorp RH, Doan QH. Have the returns to education really increased in Vietnam? Wage versus employment effect. Journal of Comparative Economics. 2013; 41:923-938.

Patrinos, HA., Barrera-Osorio, F., Guaqueta, J. The Role and Impact of Public-Private Partnerships in Education. Washington, DC: The World Bank; 2009.

Phan D, Coxhead I. Long-run costs of piecemeal reform: Wage inequality and returns to education in Vietnam. Journal of Comparative Economics. 2013; 41(4):1106-1122.

Pritchett L. Creating education systems coherent for learning outcomes: Making the transition from schooling to learning. RISE Programme working paper No. 15/005. 2015

Rolleston C, Krutikova S. Equalising opportunity? School quality and home disadvantage in Vietnam. Oxford Review of Education. 2014; 40(1):112-131.

Sakellariou C, Fang Z. The Vietnam reforms, change in wage inequality and the role of the minimum wage. Economics of Transition. 2014; 22:313-340.

Skrondal, A., Rabe-Hesketh, S. Generalized Latent Variable Modelling: Multilevel, Longitudinal, and Structural Equation Models. Boca Raton, Florida: Chapman \& Hall/CRC; 2004.

Tran, L., Marginson, S., Do, H., Do, Q., Le, T., Nguyen, N., Vu, T., Pham, T., Nguyen, H. Higher Education in Vietnam: Flexibility, Mobility and Practicality in the Global Knowledge Economy. New York: Palgrave Macmillan; 2014.

UNESCO. WIDE database. 2017. Retrieved from http://www.education-inequalities.org/

Urquiola, M. Competition among schools: Traditional public and private schools. In: Hanushek, E.Machin, S., Woessmann, L., editors. Handbook of the Economics of Education. Amsterdam: Elsevier; 2016. p. 210-237.

World Bank. Vietnam High Quality Education for All by 2020. Washington, DC: The World Bank; 2012a.

World Bank. Vietnam Workforce Development: SABER Country Report 2012. Washington, DC: The World Bank; 2012b.

World Bank. [Accessed on April 7, 2017] World Development Indicators database. 2017. http:// data.worldbank.org/data-catalog/world-development-indicators

World Bank \& Ministry of Planning and Investment of Vietnam. Vietnam 2035: Toward Prosperity, Creativity, Equity, and Democracy. Washington, DC: The World Bank; 2016.

Yuan C, Zhang L. Public education spending and private substitution in urban China. Journal of Development Economics. 2015; 115:124-139.

\section{Appendix 1: Additional Table and Data Sources}

\section{Additional Table}

Table 1.1

Attendance at Private Tutoring Classes, Vietnam 1997- 2014 (percentage)

\begin{tabular}{lcccccccc}
\hline & $\mathbf{1 9 9 7 - 9 8}$ & $\mathbf{2 0 0 2}$ & $\mathbf{2 0 0 4}$ & $\mathbf{2 0 0 6}$ & $\mathbf{2 0 0 8}$ & $\mathbf{2 0 1 0}$ & $\mathbf{2 0 1 2}$ & $\mathbf{2 0 1 4}$ \\
\hline Primary school & 31.1 & 27.9 & 31.9 & 32.3 & 34.0 & 36.3 & 36.0 & 37.9 \\
Lower secondary school & 55.9 & 42.7 & 44.7 & 45.3 & 48.4 & 50.8 & 48.4 & 53.1 \\
Upper secondary school & 76.7 & 54.4 & 58.7 & 57.6 & 60.3 & 68.1 & 63.9 & 69.7 \\
\hline
\end{tabular}

Note: Private tutoring classes are taken in addition to the lessons offered at schools, and are usually paid for by parents. The age ranges are respectively $6-10,11-14$, and 15-17 for primary school, lower secondary and upper secondary school. All estimates are weighted with population weights. No data on tutoring are available in the 1992-93 VLSS. 


\section{Data Sources}

Given that our focus is on broad trends in the education landscape in the past two to three decades, we use variables that are comparable across the different data sources. In particular, the richness of the various data sources that we analyze also comes at some cost of data comparability: the household surveys are representative of the entire population (but have no test score data), while the Grade 5 national assessment data are representative of students in that grade only, and these two data sources have different survey designs. To overcome this obstacle, we focus on the common and comparable levels (and variables) within each of the two different sources of data, thus offering a more consistent analysis that is relevant for policy. Also given the scope of this paper, we do not analyze the Young Lives survey but we provide a brief description of this survey below.

\subsection{Programme for International Student Assessment (PISA)}

The PISA is a triennial international survey which provides evaluation of 15-year-old students on benchmarked standardized tests. The PISA has been implemented by the OECD in 2000, 2003, 2006, 2009, 2012, and 2015. More than half a million students, representing 28 million 15-year-olds in 72 countries and economies, participated in the PISA in 2015. Besides offering data on student test scores, the PISA also collects a rich set of information on student, parent (optional), and school characteristics. Vietnam participated in the PISA starting in 2012, when 65 countries and economies participated, and it participated again in 2015, when the number of participating countries and economies increased to 72 . Slightly more than 5,800 students who were 15 years old in 2015 from about 190 schools across Vietnam were tested in math, reading, and science using internationally standardized test questions. While we analyze the most recent test scores from the 2015 round, we also use the 2012 round for some variables that are not available for Vietnam in the 2015 round, such as classroom hours. The data are available (http://www.oecd.org/pisa/pisaproducts/) and have been widely analyzed by governments, international agencies, and researchers for insights into educational policies.

\subsection{Grade 5 Assessment}

The Grade 5 Assessment survey implements national large-scale evaluations of Grade 5 students. It has been implemented in 2001, 2007, 2011, and 2015 by Vietnam's Ministry of Education. The 2001 round received strong technical assistance from the World Bank. Each survey round collects data on approximately 60,000 students from around 4,000 primary schools across the country. Besides standardized test scores, the Grade 5 Assessment survey also collects data on a number of student and parental characteristics, teacher (and principal) qualifications and experience, as well as school infrastructure. Application for the data can be made to the MoET, Vietnam. The 2001 and 2007 rounds have been analyzed in several publications including World Bank (2012b) and Nguyen and Griffin (2010).

\subsection{Vietnam Living Standards Surveys (VLSS) and Vietnam Household Living Standards Surveys (VHLSS)}

The General Statistics Office of Vietnam has implemented nationally representative household surveys in 1992-1993, 1997-1998, 2002, 2004, 2006, 2008, 2010, 2012, and 
2014. The 1992-1993 and 1997-1998 surveys are known as the Vietnam Living Standards Surveys (VLSS). Starting in 2002, they were renamed the Vietnam Household Living Standards Surveys (VHLSS) are were implemented biennially. The 1992-1993 and 19971998 VLSS rounds collected data on 4,800 and 6,000 households, respectively, while the 2002 VHLSS round collected income and expenditure data on 45,000 households. Since 2004, the VHLSS has collected income and expenditure data on approximately 9,000 households. The household questionnaire collects detailed information on household expenditures, and standard information on education: enrollment, years of schooling, and highest degree of education for all household members. The VHLSS also has a community (commune) questionnaire for rural areas that collects information on the availability of different types of schools, as well as some basic information about their characteristics. The VHLSS data can be obtained by writing to the General Statistical Office in Hanoi. Instructions on how to obtain the data are available at http://econ.worldbank.org/WBSITE/ EXTERNAL/EXTDEC/EXTRESEARCH/EXTLSMS/0,,contentMDK:21482640 menuPK: 4196952 pagePK:64168445 piPK:64168309 theSitePK:3358997,00.html). The VHLSS data have been widely analyzed by the Government of Vietnam, international donors, and researchers for insights into educational policies.

\subsection{Primary School Census (PSC)}

Vietnam's Ministry of Education and Training (MoET) has collected primary school census (PSC) data annually on all primary schools in the country. It was supported by a World Bank project between 2005 and 2011, and is currently implemented by MoET. The PSC collects detailed information on school infrastructure and quality and students. For example, the collected data include the number of students who are currently enrolled or who repeat classes, which are further disaggregated by grade, gender, age, ethnicity, and disability status. These data are provided by school principals (or the most knowledgeable school official). The PSC data can be obtained by writing to the MoET in Hanoi, Vietnam. The data have been analyzed in a few publications including Attfield and Vu (2013) and Dang and Rogers (2016).

\subsection{Young Lives Survey (YL)}

Young Lives is an international study of childhood poverty following the lives of 12,000 children in Ethiopia, India (in the states of Andhra Pradesh and Telangana), Peru and Vietnam over 15 years, from 2002 to 2017. Two cohorts of children-2,000 children born in 2001-02, and 1,000 born in 1994-95-are followed in all four countries. In Vietnam, the YL survey has been implemented in 5 provinces (out of 63 provinces in all of Vietnam). These children belong to households that are poorer, and have less access to basic social utilities than the average household in the country. The YL has been implemented for Vietnam in 2002, 2006, 2009, 2013, and 2016. These data are publicly available (http:// www.younglives.org.uk/content/use-our-data). The YL data have been widely analyzed by researchers for insights into educational policies. 

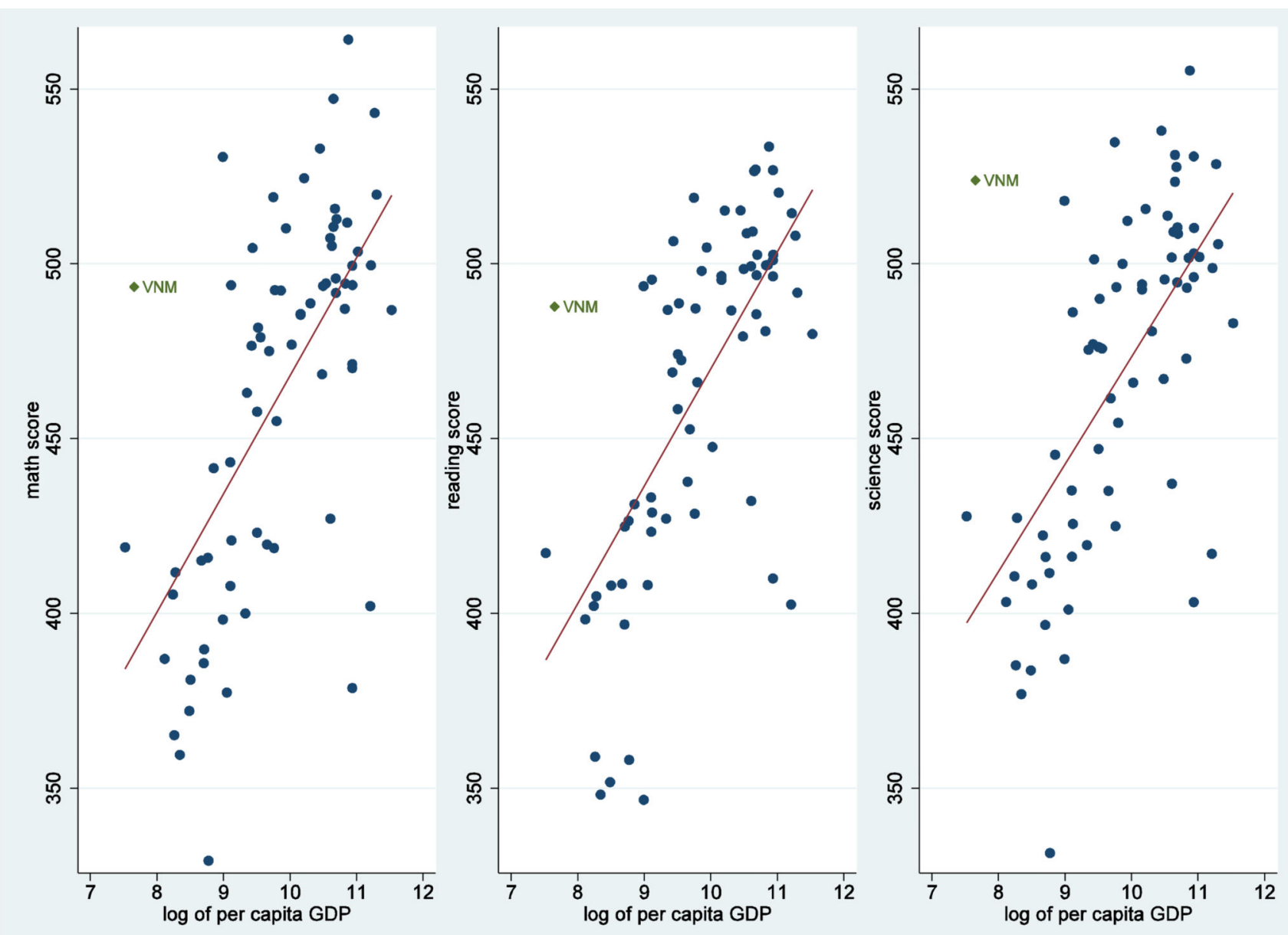

Figure 1.

PISA Test Scores vs. Country Income Level, 2015

Data source: PISA database and World Bank's WDI database. 


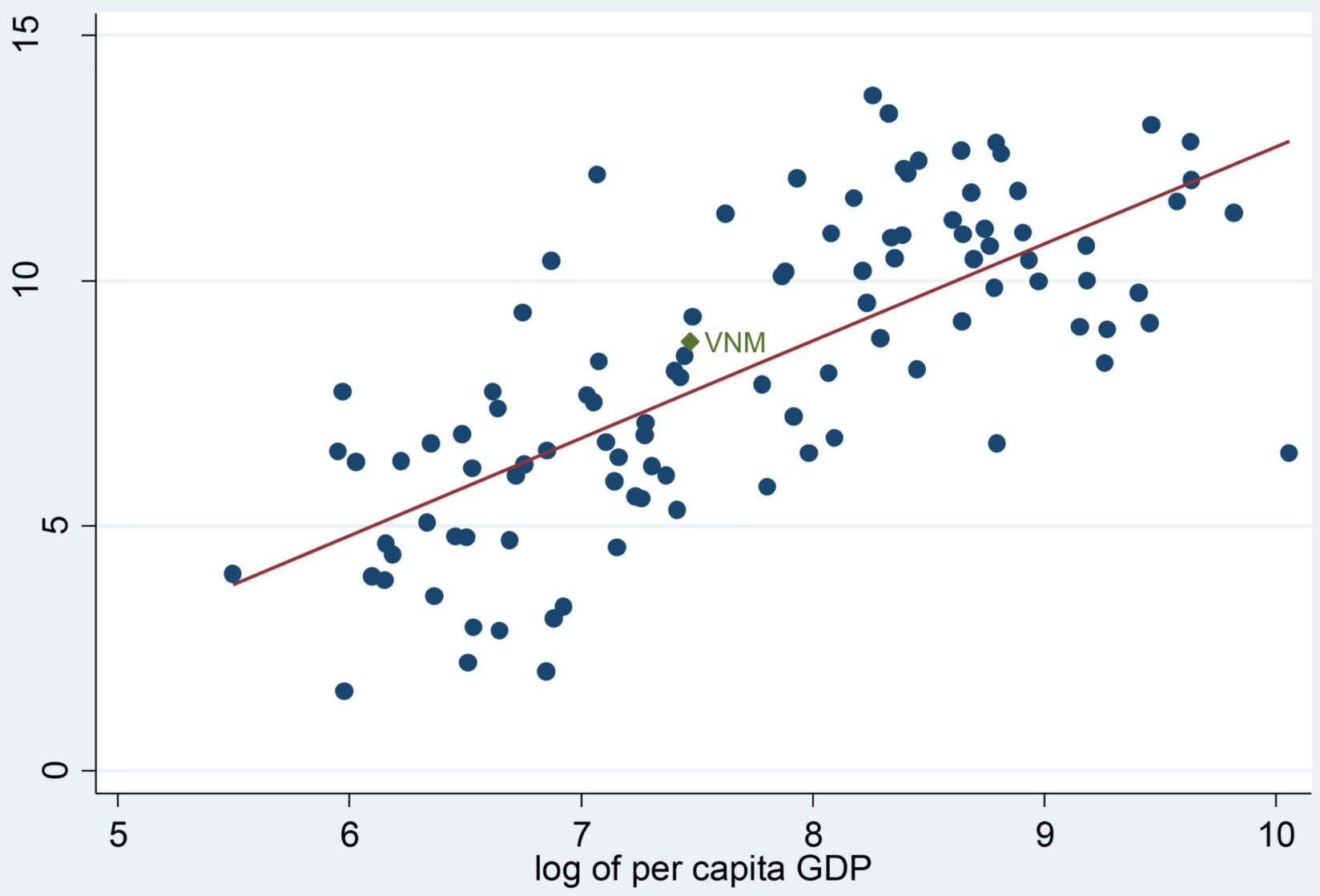

Note: education achievement is obtained from household surveys implemented between 2000 and 2014; GDP data are from 2012

Figure 2.

Mean Years of Schooling of Adult Population vs. Country Income Level

Data source: UNESCO's WIDE database and World Bank's WDI database. 


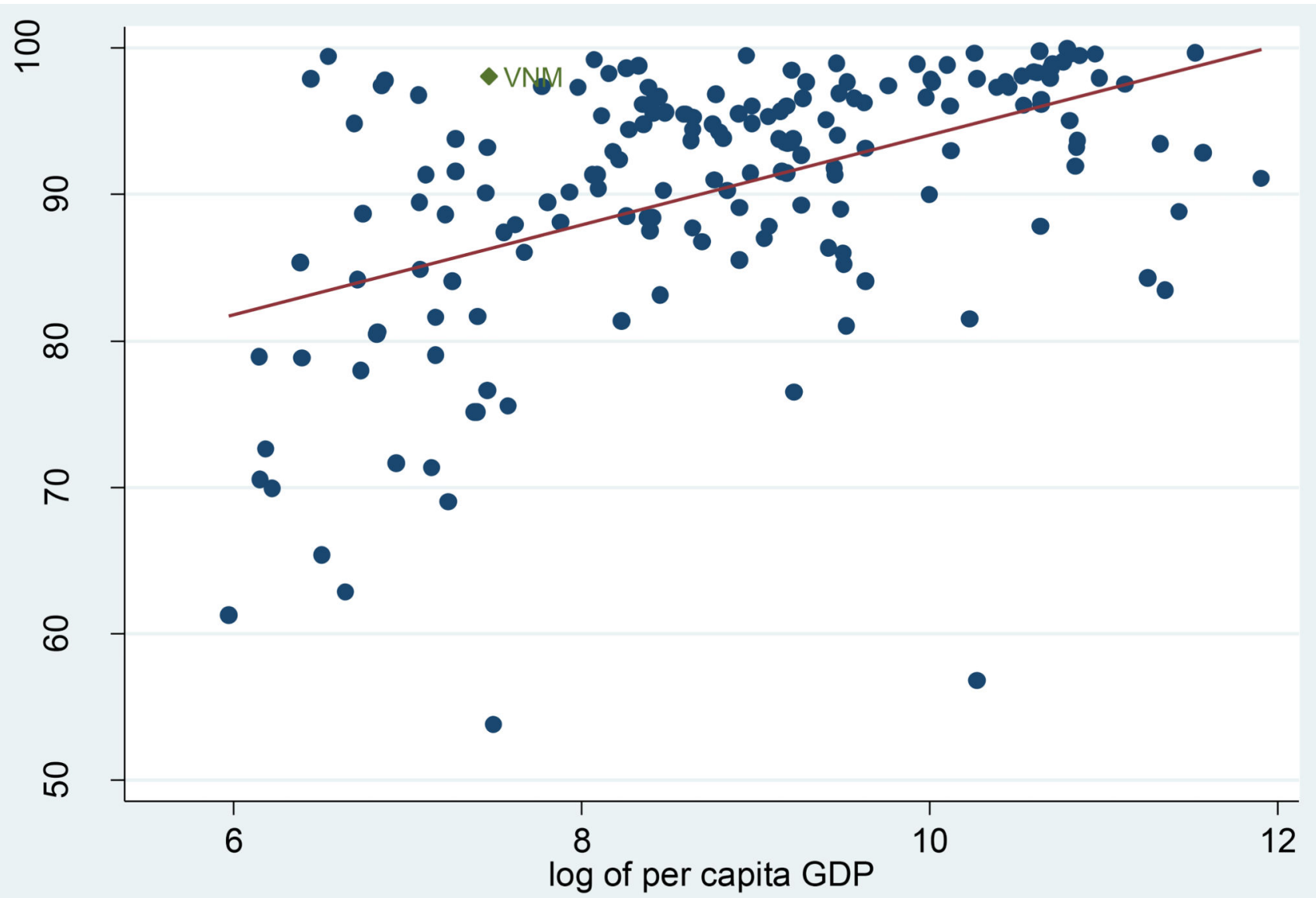

Note: both net primary school enrolment and GDP data are from 2012.

Figure 3.

Net Primary School Enrollment vs. Country Income Level

Data source: World Bank’s WDI database. 


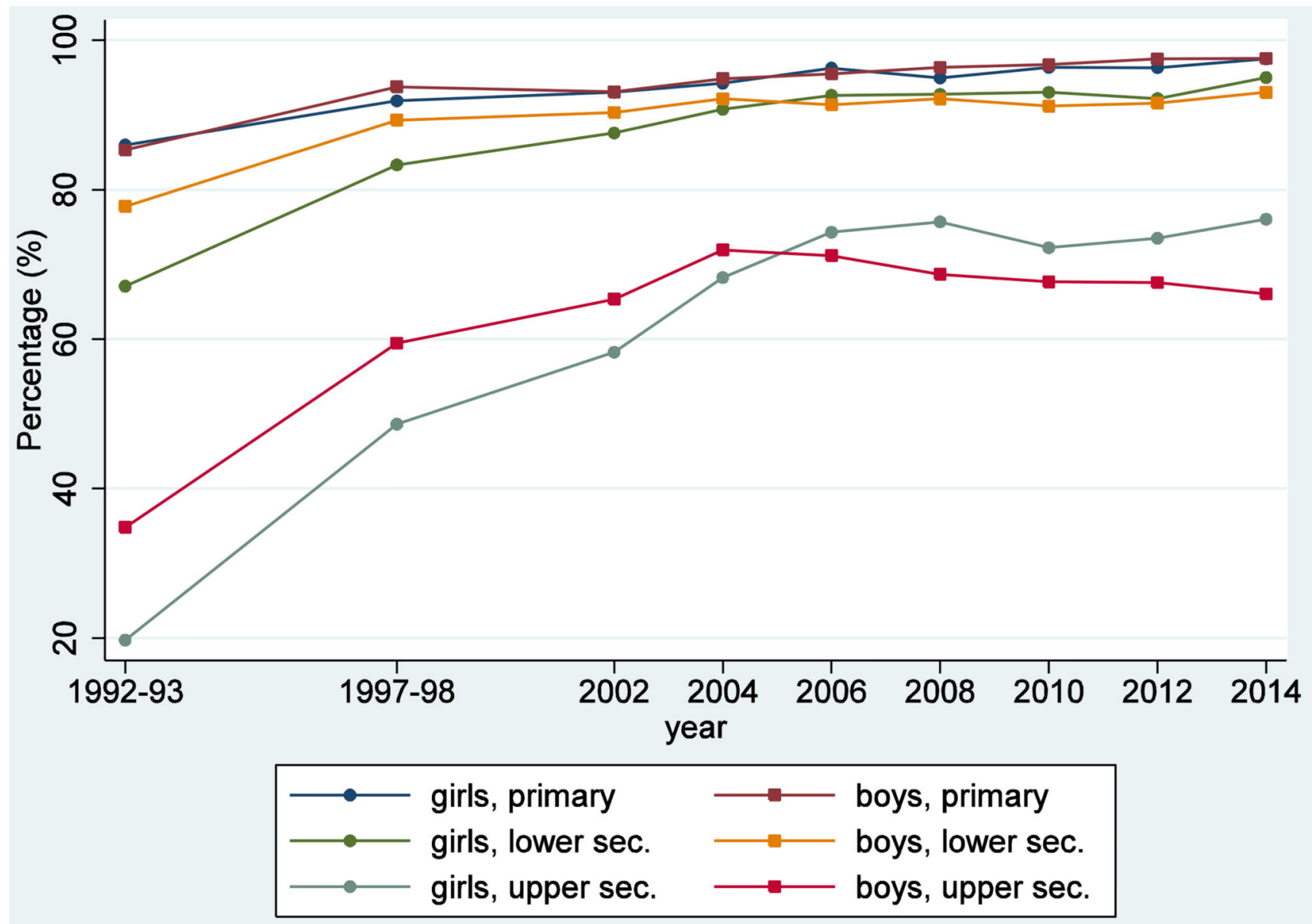

Figure 4.

Net Enrollment Rate by School Level and Gender, Vietnam 1992- 2014 (percentage)

Data source: VHLSS. 

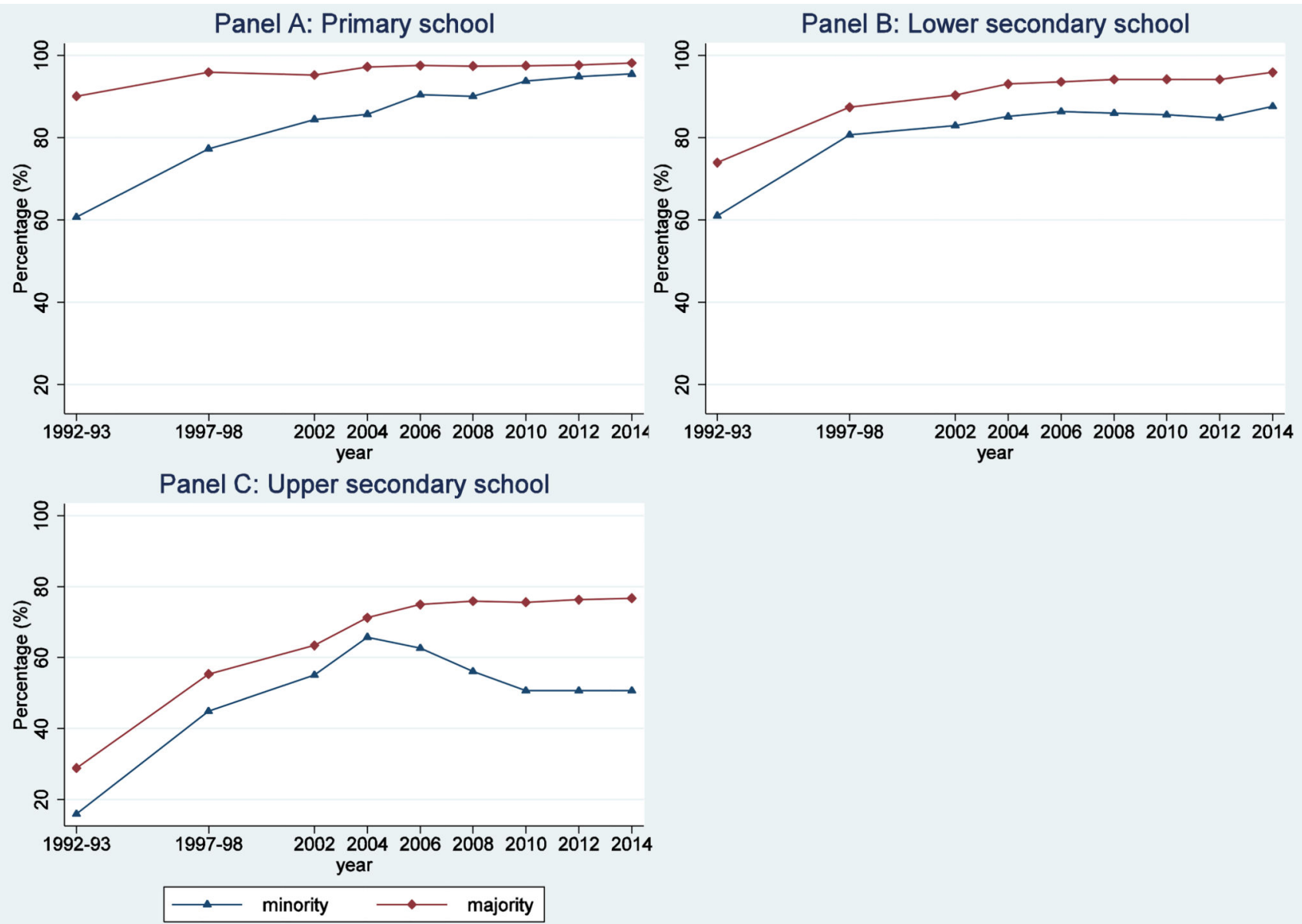

Figure 5.

Net Enrollment Rate by School Level and Ethnicity, Vietnam 1992- 2014 (percentage)

Data source: VHLSS. 


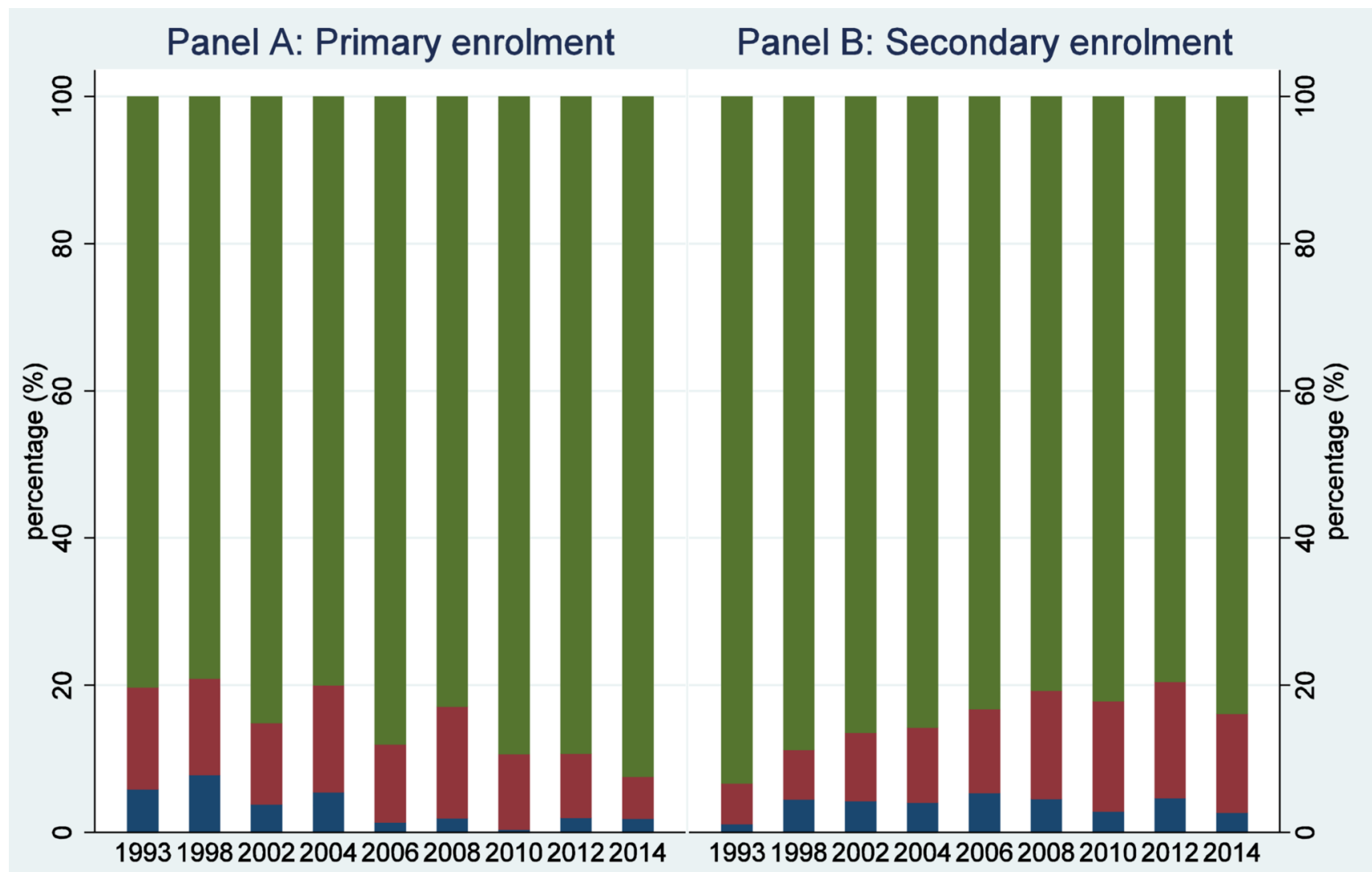

Note: green, maroon, and blue bars represent the contribution to the total variations in enrollment from student, commune, and province respectively.

Figure 6.

Proportion of the Variance in School Enrollment Due to Variation in Student, Commune and Province Factors, Vietnam 1992- 2014 (percentage)

Data source: VHLSS. 


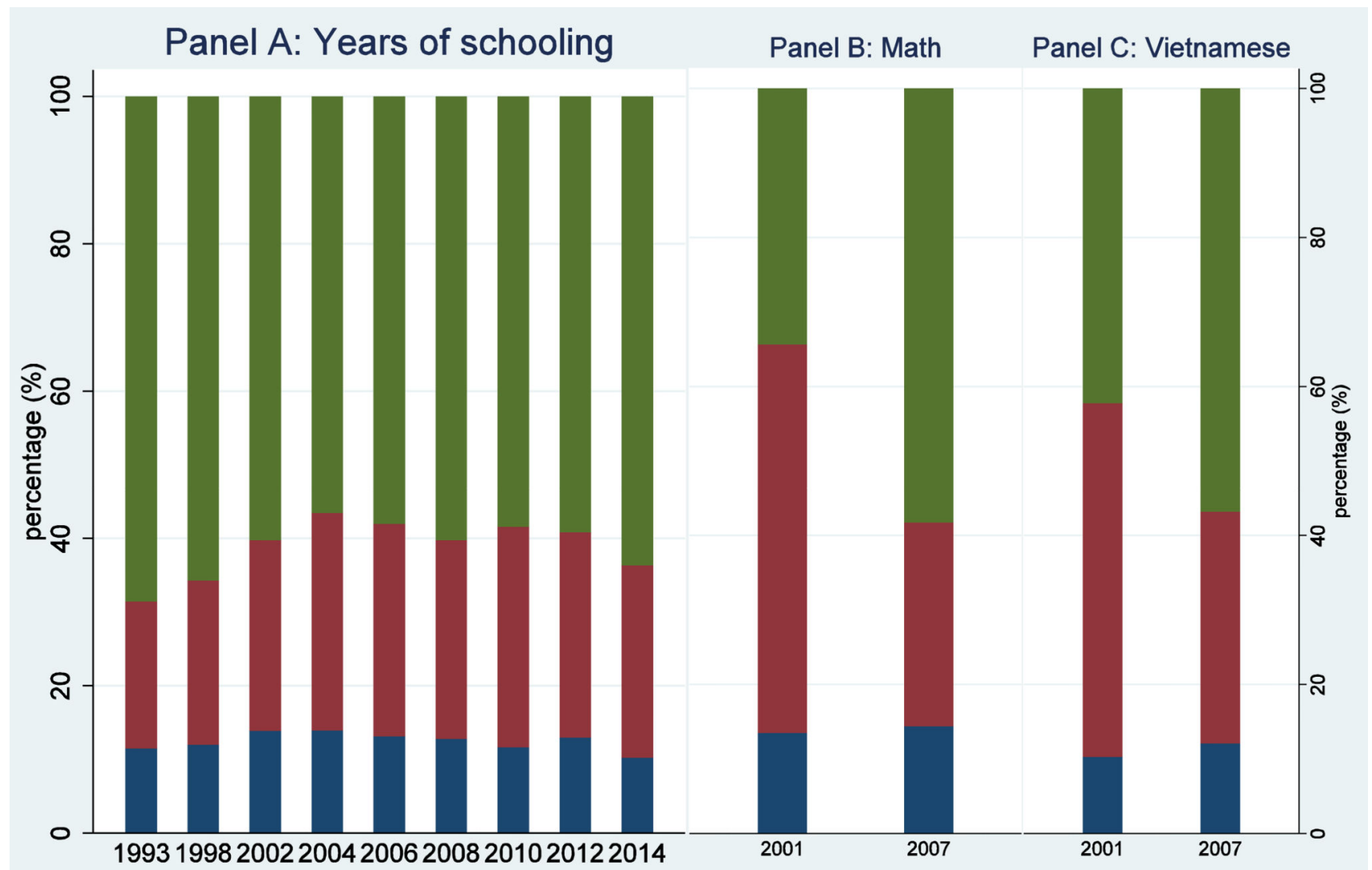

Note: green, maroon, and blue bars represent the contribution to the total variations in years of schooling (panel A) and test scores (panels $B$ and $C$ ) from student, commune, and province respectively.

Figure 7.

Proportion of the Variance in Education Achievement Due to Variation in Student, Commune and Province Factors, Vietnam 2002- 2014 (percentage)

Data source: VHLSS and Grade 5 Assessment. 


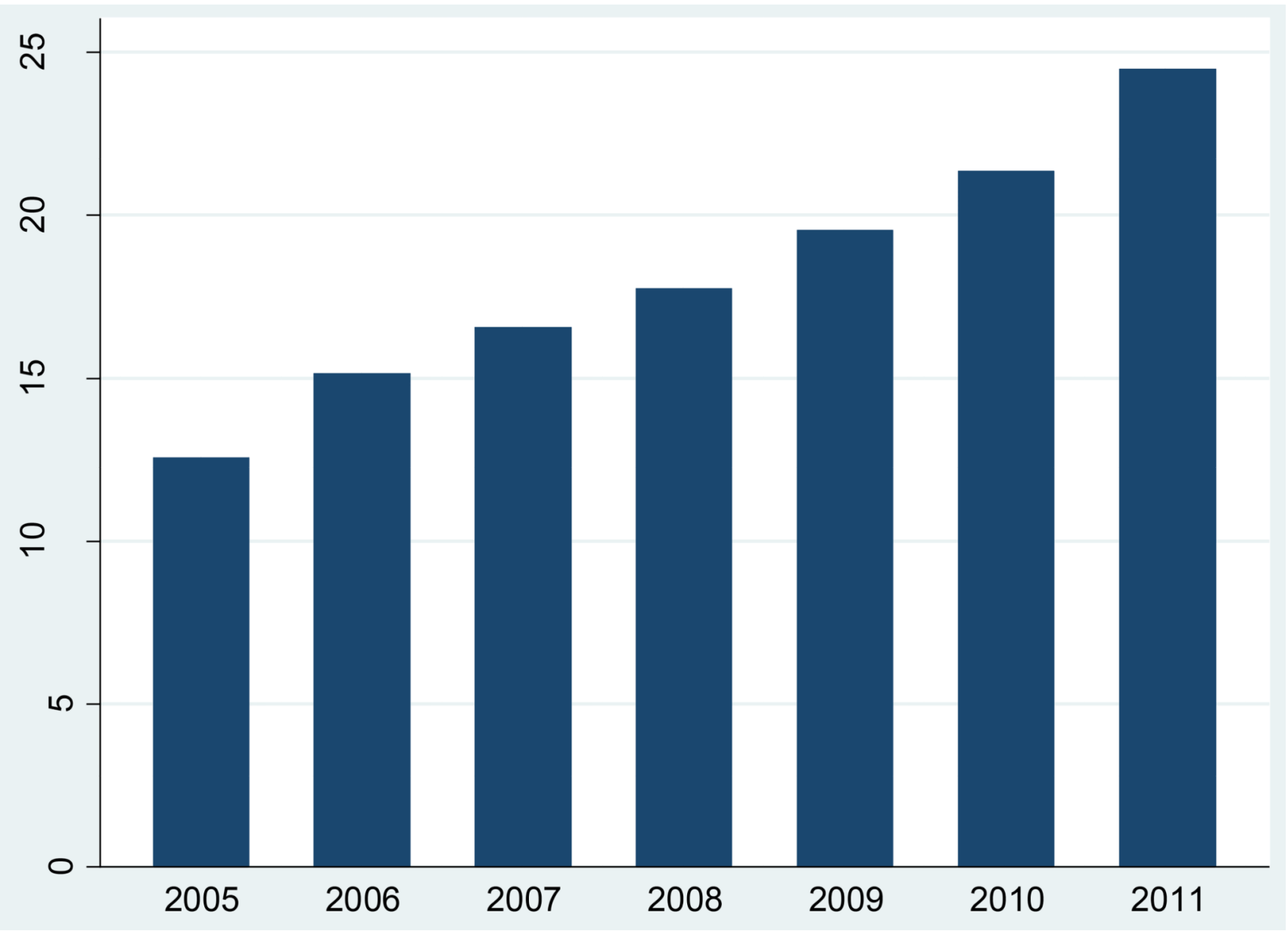

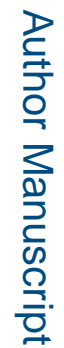

Figure 8.

Percentage of Primary Schools that Meet National Standards of Quality, Vietnam 20052011

Data source: Primary School Census database. 


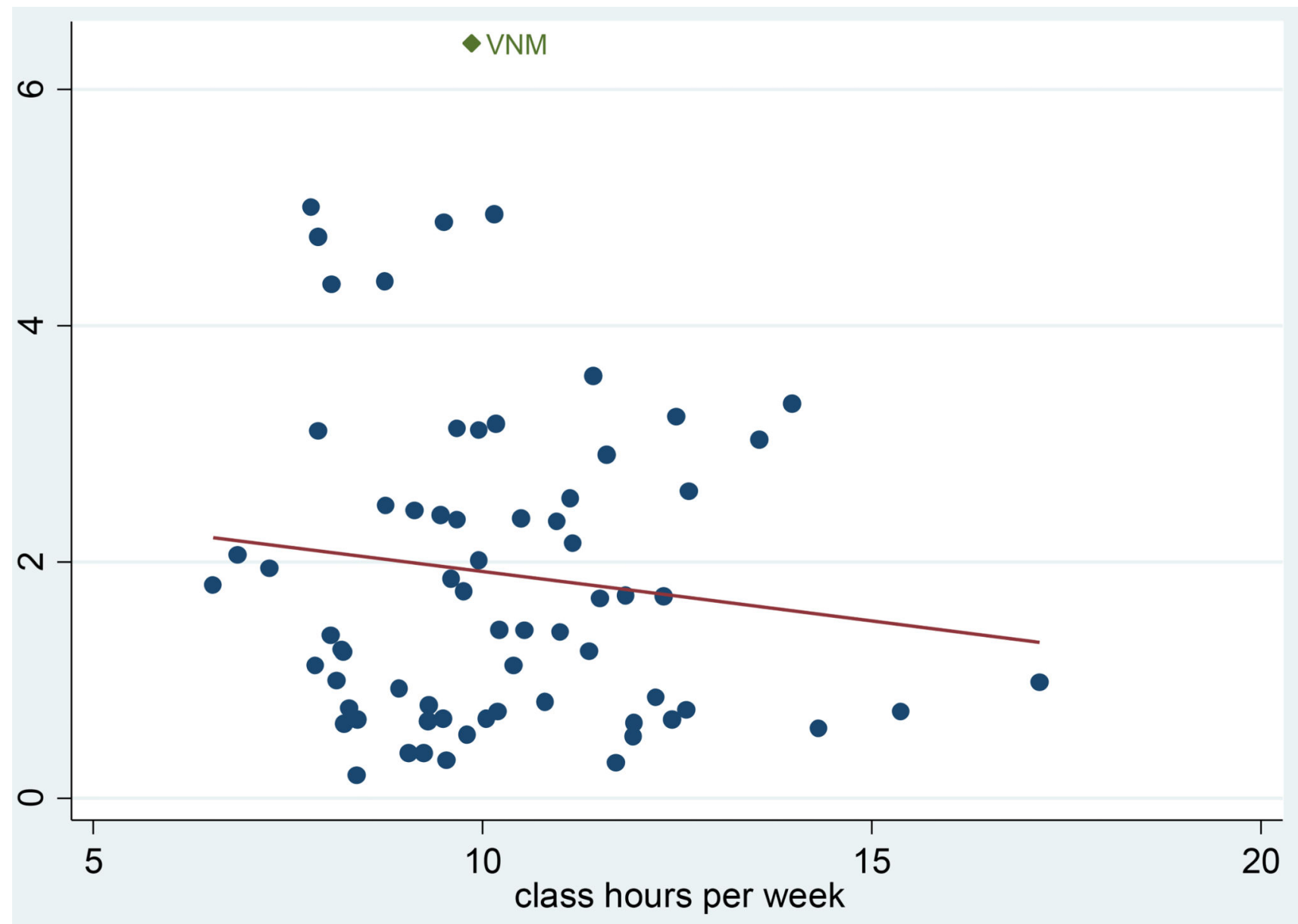

Note: weekly class hours are in math, language, and science.

Figure 9.

Average Tutoring Hours vs. Weekly Classroom Hours in Math, Science, and Language, PISA 2012

Data source: PISA database. 

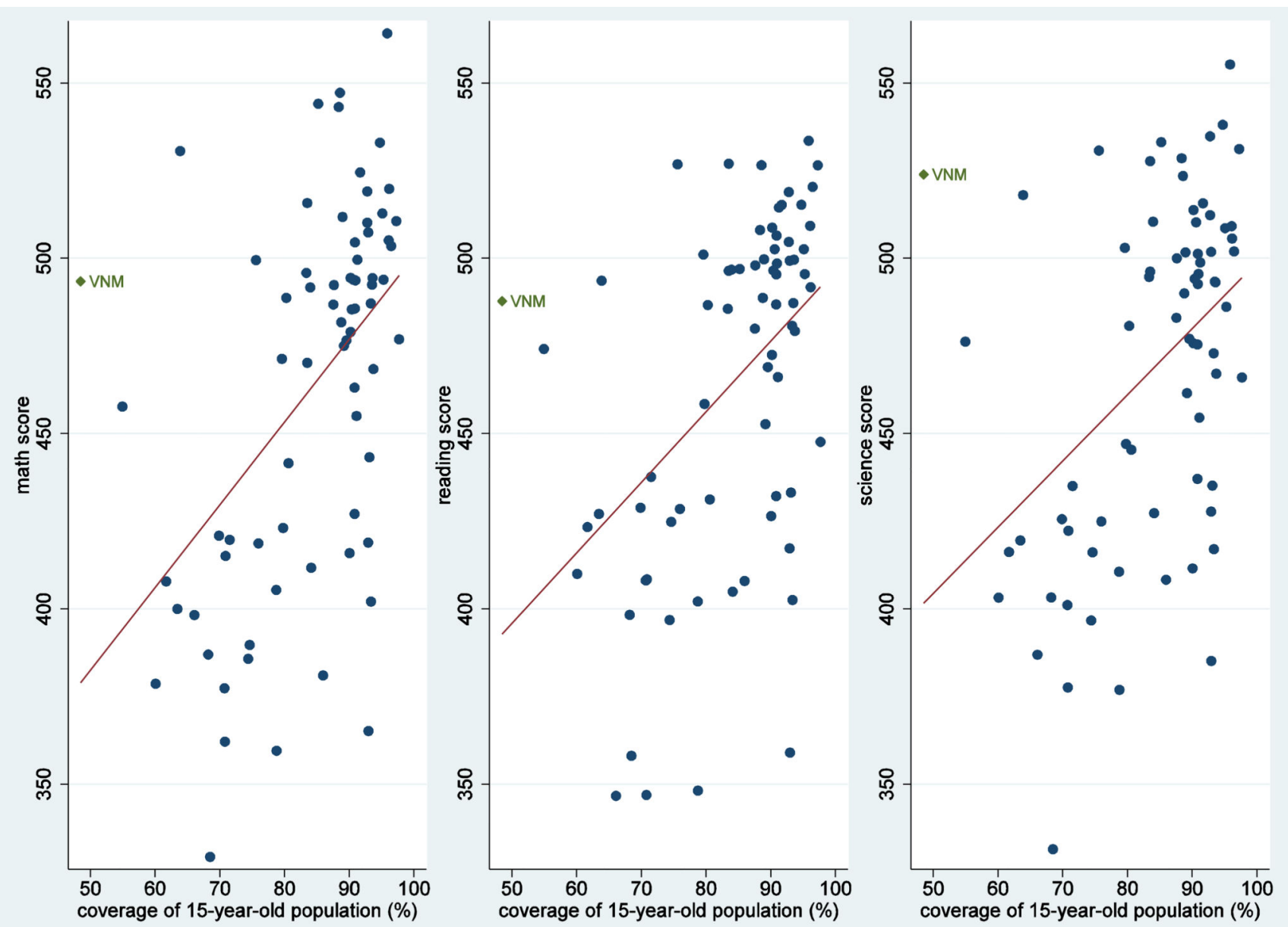

Figure 10.

Test Scores vs. Enrollment Rate of 15-Year-Old Population, PISA 2015

Data source: PISA database. 

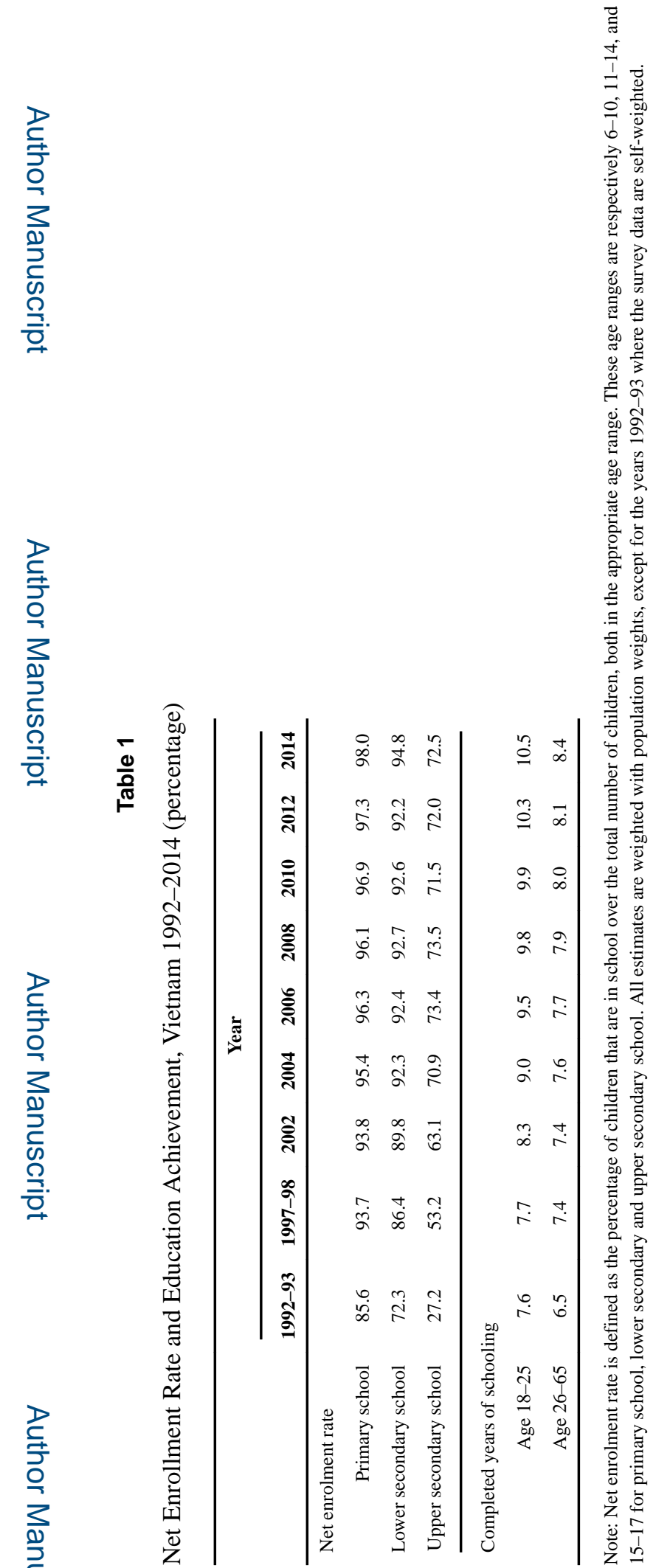

를
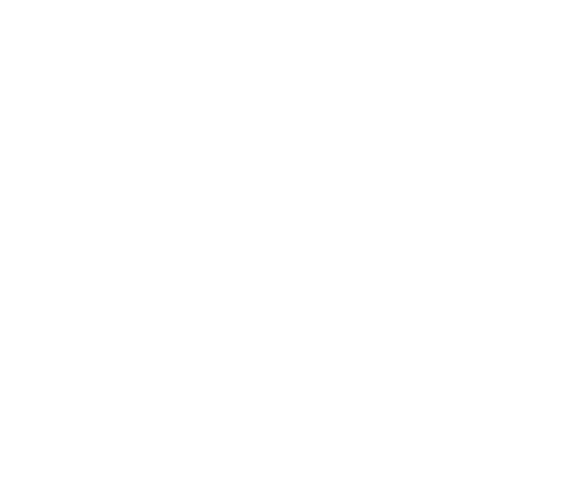

产

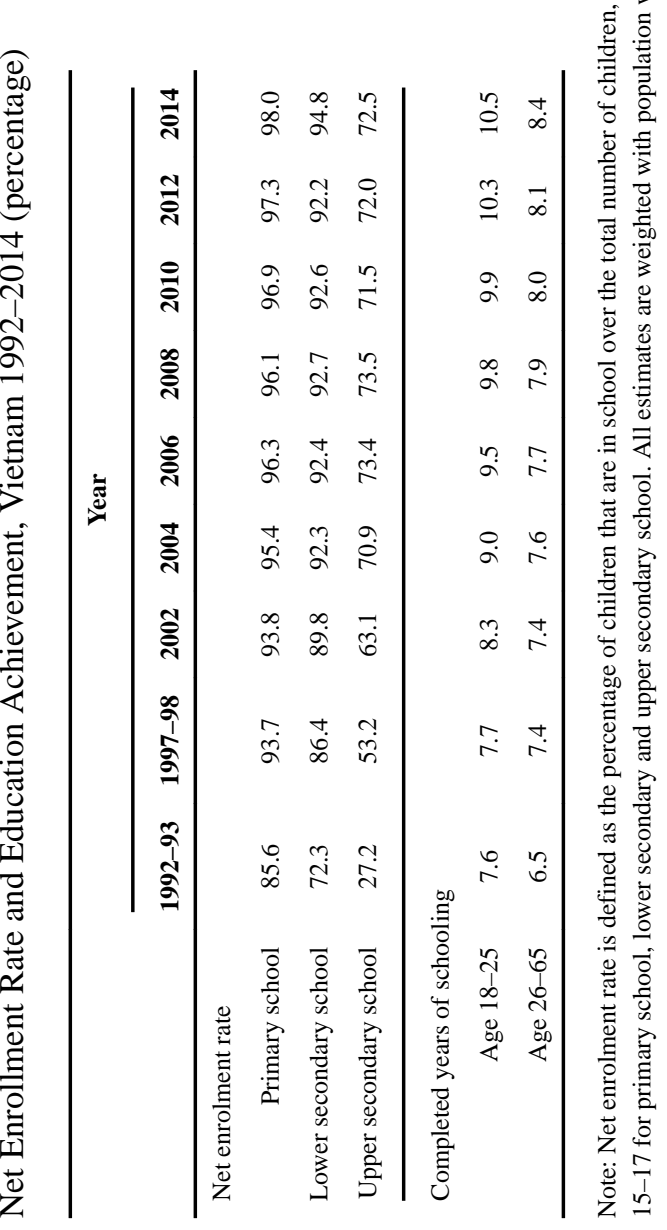

J Dev Stud. Author manuscript; available in PMC 2018 June 20. 


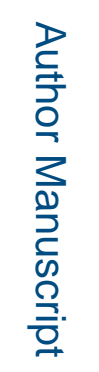

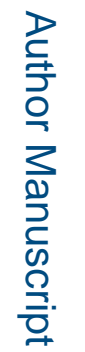

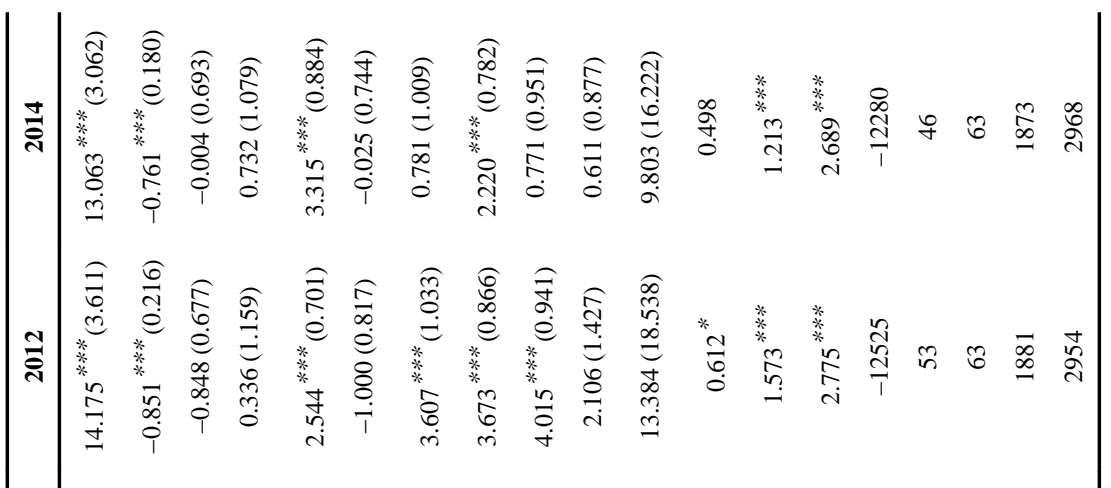

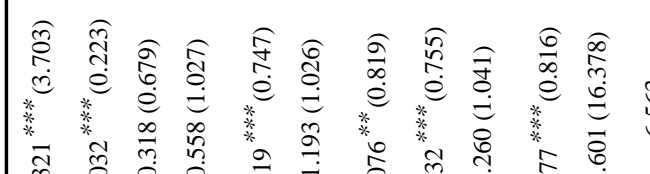

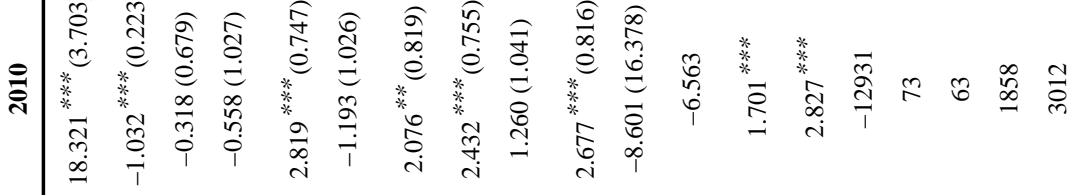

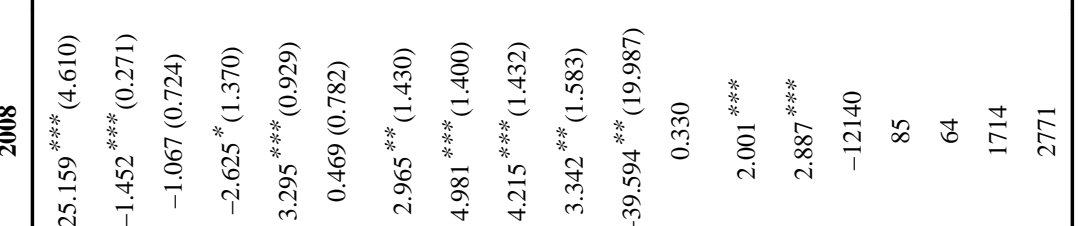

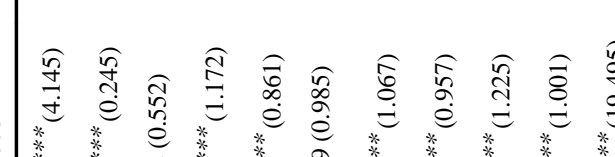

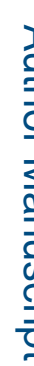

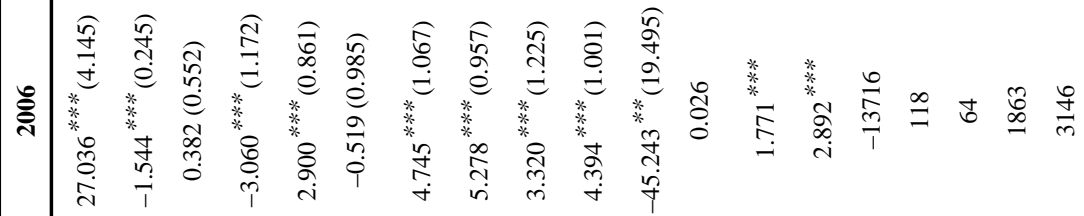

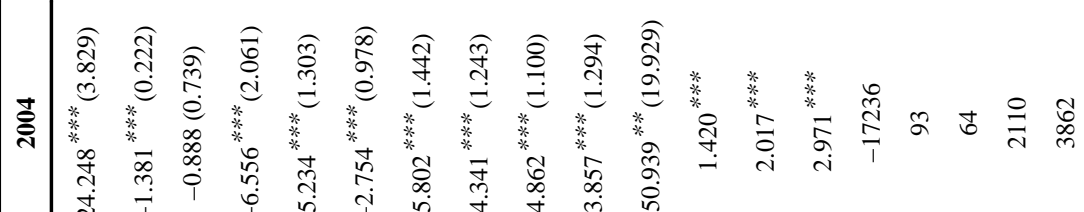

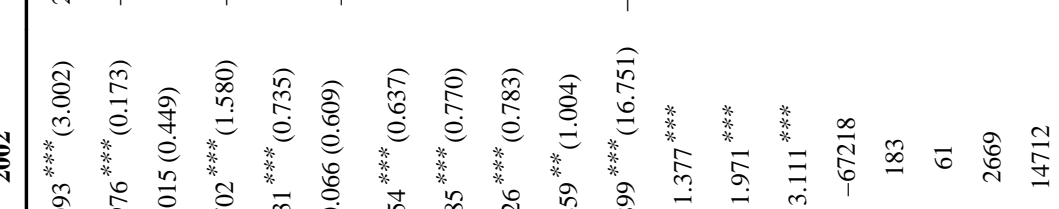

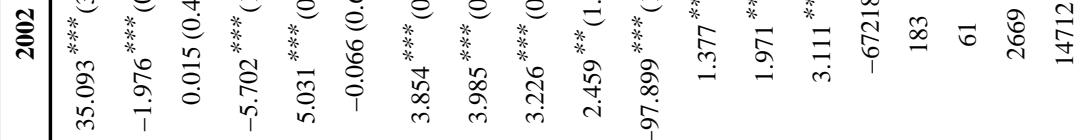

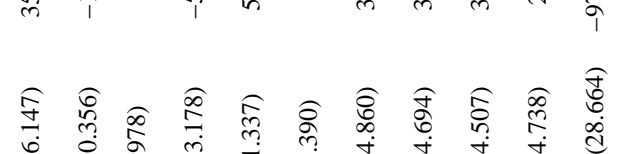

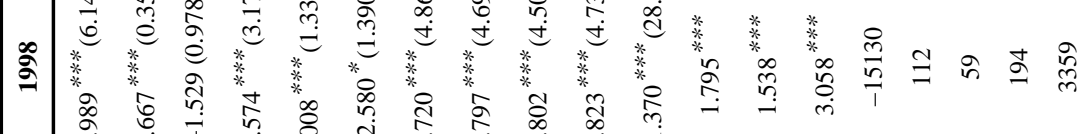

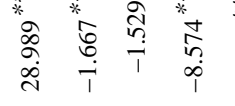




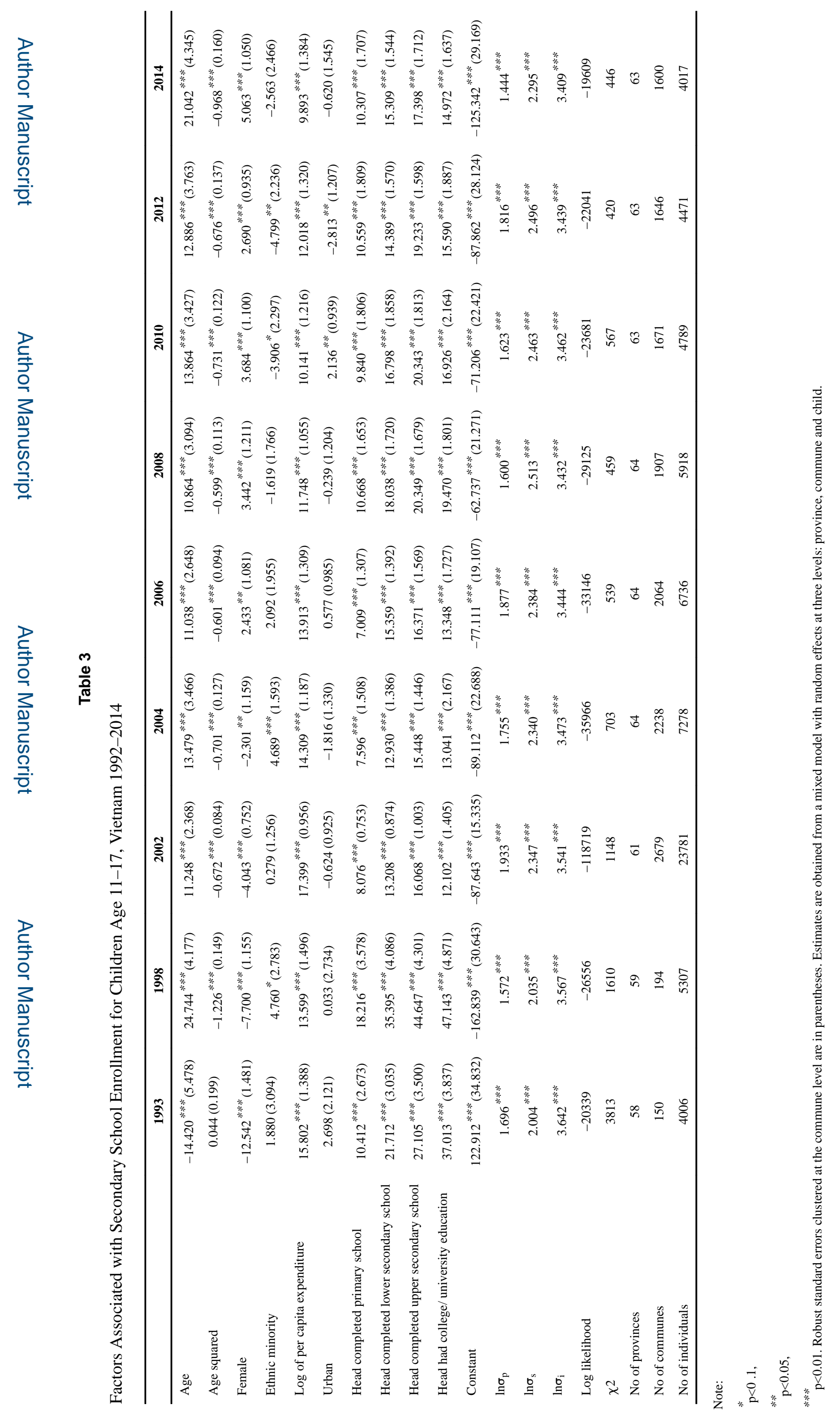




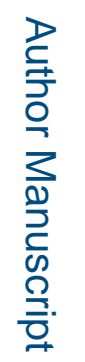

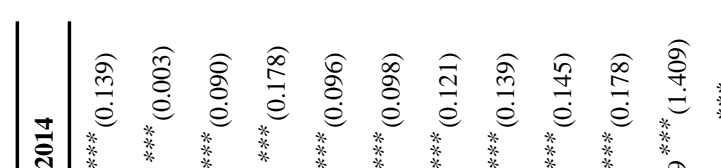

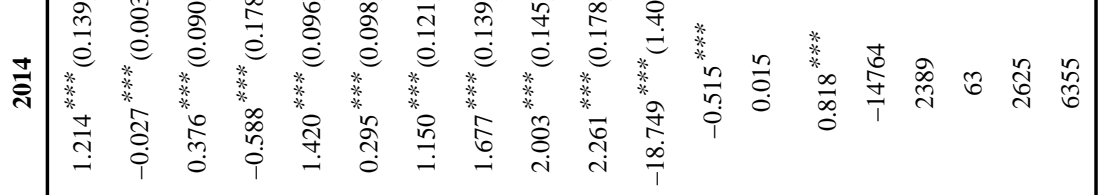

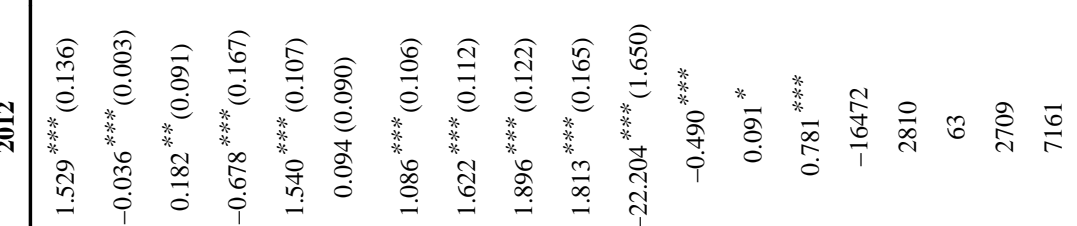

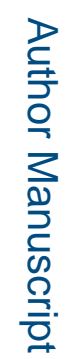

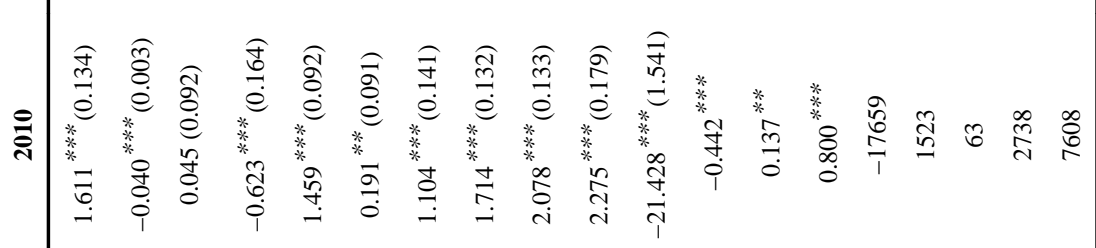

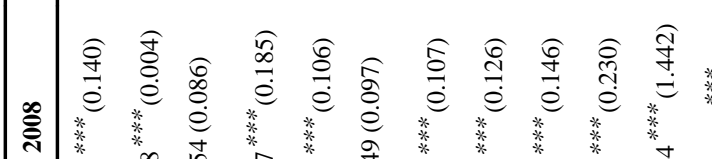

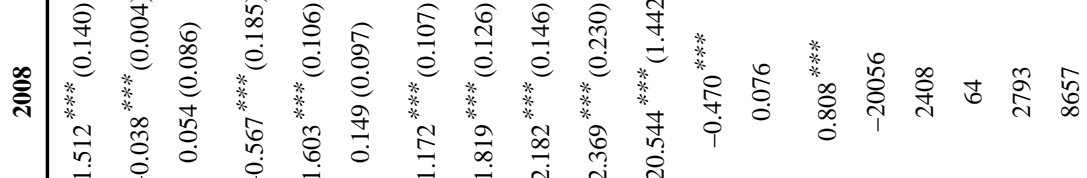

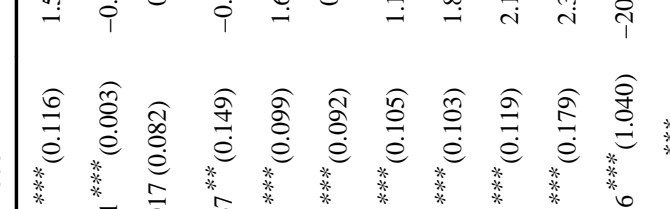

孛

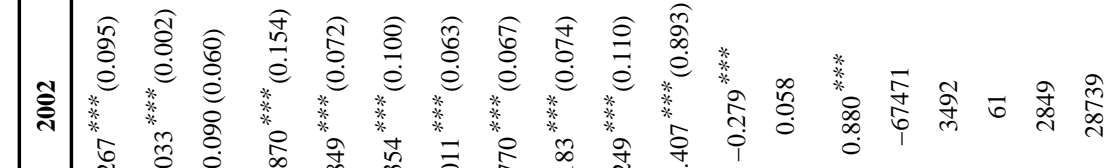

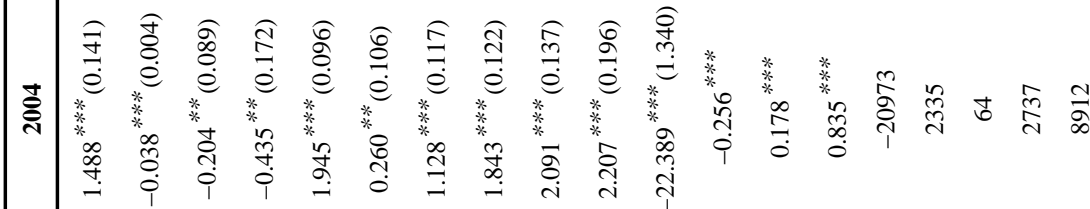

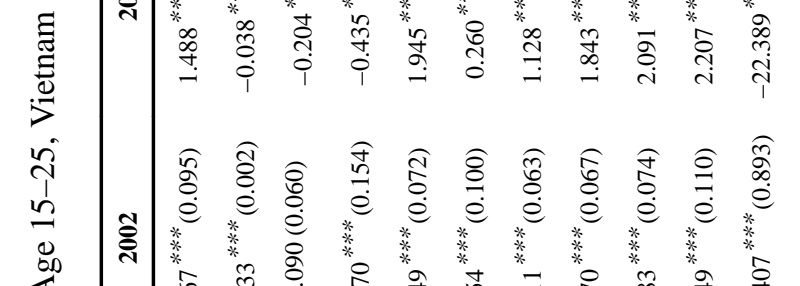

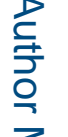

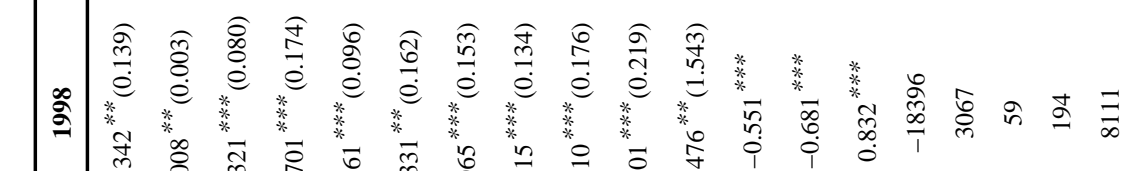

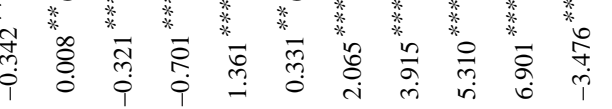

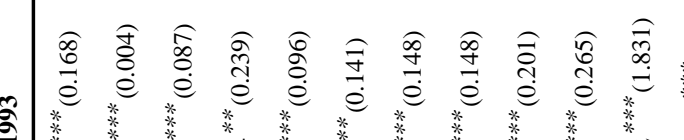

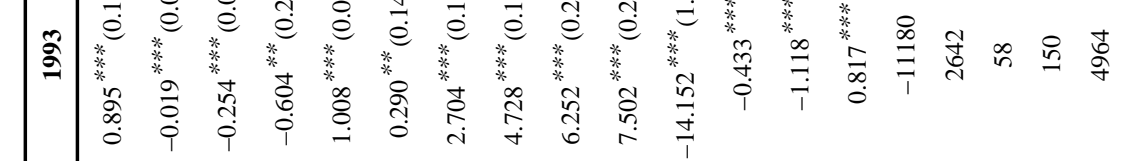

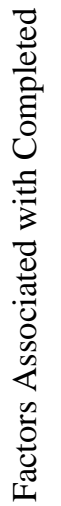

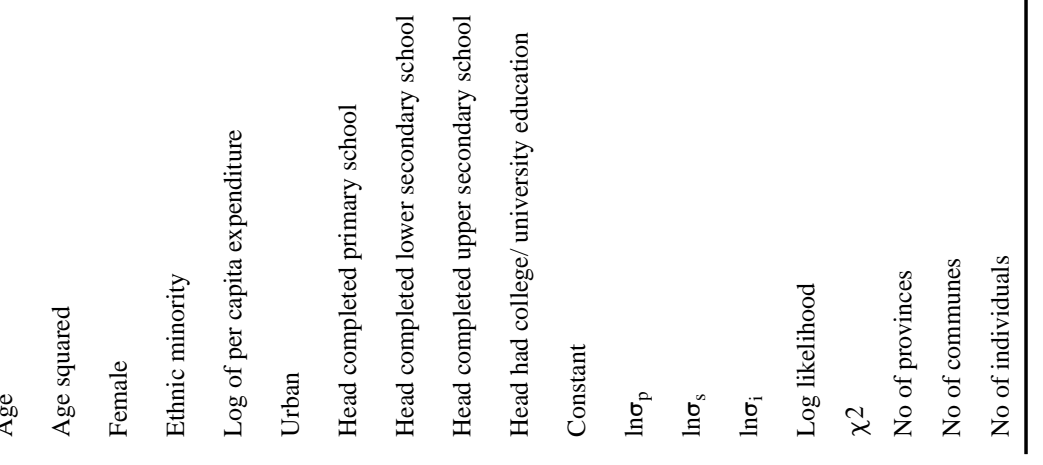


Table 5

Determinants of Test Scores for Grade 5 Students, Vietnam 2001- 2007

\begin{tabular}{|c|c|c|c|c|}
\hline & \multicolumn{2}{|c|}{2001} & \multicolumn{2}{|c|}{2007} \\
\hline & Math & Vietnamese & Math & Vietnamese \\
\hline Age & $-0.162^{* * *}(0.031)$ & $-0.229^{* * * *}(0.045)$ & $-0.620^{* * * *}(0.085)$ & $-0.381^{* * * *}(0.068)$ \\
\hline Age squared & $0.005^{* * *}(0.001)$ & $0.007^{* * *}(0.002)$ & $0.021^{* * *}(0.003)$ & $0.012^{* * * *}(0.003)$ \\
\hline Female & $-0.029^{* * *}(0.005)$ & $0.096^{* * *}(0.006)$ & $0.025^{* * *}(0.008)$ & $0.180^{* * *}(0.008)$ \\
\hline Ethnic minority & $-0.100^{* * *}(0.017)$ & $-0.141^{* * * *}(0.022)$ & $-0.254^{* * *}(0.027)$ & $-0.183^{* * * *}(0.024)$ \\
\hline Household asset index & $0.036^{* * *}(0.002)$ & $0.035^{* * *}(0.002)$ & $0.070^{* * *}(0.003)$ & $0.052^{* * * *}(0.002)$ \\
\hline Urban & $0.274^{* * *}(0.036)$ & $0.273^{* * * *}(0.034)$ & $0.303^{* * *}(0.032)$ & $0.291^{* * * *}(0.025)$ \\
\hline Head completed primary school & $0.032^{* *}(0.013)$ & $0.059^{* * *}(0.013)$ & $0.138^{* * *}(0.019)$ & $0.124^{* * * *}(0.020)$ \\
\hline Head completed lower secondary school & $0.093^{* * *}(0.013)$ & $0.137^{* * *}(0.015)$ & $0.270^{* * * *}(0.021)$ & $0.227^{* * *}(0.020)$ \\
\hline Head completed upper secondary school & $0.245^{* * *}(0.015)$ & $0.294^{* * *}(0.015)$ & $0.469^{* * * *}(0.027)$ & $0.395^{* * * *}(0.021)$ \\
\hline Head had college/ university education & $0.258^{* * *}(0.018)$ & $0.306^{* * * *}(0.020)$ & $0.357^{* * * *}(0.026)$ & $0.319^{* * * *}(0.023)$ \\
\hline Constant & $0.812^{* * *}(0.190)$ & $1.257^{* * *}(0.272)$ & $3.907^{* * * *}(0.549)$ & $2.293^{* * * *}(0.437)$ \\
\hline $\ln \sigma_{\mathrm{p}}$ & $-1.124^{* * *}$ & $-1.349^{* * *}$ & $-1.061^{* * *}$ & $-1.446^{* * *}$ \\
\hline $\ln \sigma_{\mathrm{s}}$ & $-0.363^{* * *}$ & $-0.424^{* * *}$ & $-0.569^{* * *}$ & $-0.759^{* * *}$ \\
\hline $\ln \sigma_{\mathrm{i}}$ & $-0.544^{* * *}$ & $-0.447^{* * *}$ & $-0.072 * * *$ & $-0.335^{* * *}$ \\
\hline Log likelihood & -66417 & -72537 & -77591 & -63246 \\
\hline$\chi^{2}$ & 1238 & 1406 & 2004 & 2096 \\
\hline No of provinces & 61 & 61 & 64 & 64 \\
\hline No of schools & 3627 & 3627 & 3841 & 3841 \\
\hline No of students & 68921 & 68923 & 54920 & 54799 \\
\hline
\end{tabular}

Note:

$\mathrm{p}<0.1$

**

$\mathrm{p}<0.05$,

***

$\mathrm{p}<0.01$. Robust standard errors clustered at the commune level are in parentheses. Estimates are obtained from a mixed model with random effects at three levels: province, commune and child. Test scores in 2007 are standardized by the distributions in 2001. The household asset index is a variable that counts the number of assets in a student's home from a common list of assets between the two survey rounds, which includes clock, lamp, desk, chair, telephone (desk phone or mobile phone), bookcase, radio (and radio cassette), television, computer, bicycle, and motorbike. 